Article

\title{
Examining Landscape-Scale Fuel and Terrain Controls of Wildfire Spread Rates Using Repetitive Airborne Thermal Infrared (ATIR) Imagery
}

\author{
Gavin M. Schag ${ }^{1, *}$, Douglas A. Stow ${ }^{1}$, Philip J. Riggan ${ }^{2}$, Robert G. Tissell ${ }^{2}$ and Janice L. Coen ${ }^{3}$ (i) \\ 1 Department of Geography, San Diego State University, San Diego, CA 92182, USA; stow@sdsu.edu \\ 2 USDA Forest Service, Pacific Southwest Research Station, Riverside, CA 96002, USA; \\ philip.riggan@usda.com (P.J.R.); robert.tissell@usda.com (R.G.T.) \\ 3 National Center for Atmospheric Research, P.O. Box 3000, Boulder, CO 80301, USA; janicec@ucar.edu \\ * Correspondence: gschag@sdsu.edu
}

Citation: Schag, G.M.; Stow, D.A.; Riggan, P.J.; Tissell, R.G.; Coen, J.L. Examining Landscape-Scale Fuel and Terrain Controls of Wildfire Spread Rates Using Repetitive Airborne

Thermal Infrared (ATIR) Imagery. Fire 2021, 4, 6. https://doi.org/10.3390/ fire 4010006

Received: 4 January 2021

Accepted: 29 January 2021

Published: 3 February 2021

Publisher's Note: MDPI stays neutral with regard to jurisdictional claims in published maps and institutional affiliations.

Copyright: (c) 2021 by the authors. Licensee MDPI, Basel, Switzerland. This article is an open access article distributed under the terms and conditions of the Creative Commons Attribution (CC BY) license (https:// creativecommons.org/licenses/by/ $4.0 /)$.

\begin{abstract}
The objectives of this study are to evaluate landscape-scale fuel and terrain controls on fire rate of spread (ROS) estimates derived from repetitive airborne thermal infrared (ATIR) imagery sequences collected during the 2017 Thomas and Detwiler extreme wildfire events in California. Environmental covariate data were derived from prefire National Agriculture Imagery Program (NAIP) orthoimagery and USGS digital elevation models (DEMs). Active fronts and spread vectors of the expanding fires were delineated from ATIR imagery. Then, statistical relationships between fire spread rates and landscape covariates were analyzed using bivariate and multivariate regression. Directional slope is found to be the most statistically significant covariate with ROS for the five fire imagery sequences that were analyzed and its relationship with ROS is best characterized as an exponential growth function (adj. $\mathrm{R}^{2} \max =0.548, \min =0.075$ ). Imaged-derived fuel covariates alone are statistically weak predictors of $\operatorname{ROS}\left(\operatorname{adj} . R^{2} \max =0.363, \min =0.002\right)$ but, when included in multivariate models, increased ROS predictability and variance explanation $(+14 \%)$ compared to models with directional slope alone.
\end{abstract}

Keywords: wildland fire; extreme wildfire event; fire rate of spread; thermal imagery; regression

\section{Introduction}

Wildfires induce a variety of valuable ecosystem processes [1,2] but can inflict severe economic, social, and environmental losses. Of note, California's 2017 losses include USD 500 million in suppression costs, 47 lives lost, and over 9000 structures damaged or destroyed [3]. These statistics highlight the need to understand how fire behavior is related to underlying geospatially distributed environmental factors. Rate of spread (ROS), also referred to as fire spread rate, is a key focus of fire scientists, first responders, and fire management agencies and has been the subject of many studies seeking to quantify its dependence on environmental factors. Research on the mechanisms that govern wildfire spread are commonly conducted using laboratory [4-7] or outdoor fire experiments [8-10], where inputs may be controlled by researchers. Findings discerned from such studies have been extended to larger spatial scales using numerical models that simulate wildfire spread in various environments and conditions e.g., [11-14].

Laboratory studies and fire spread models have utility, however, advancements are stymied by the lack of quality landscape-scale data needed for adequate fire spread theory, model validation, and model calibration [15-19]. There is also a need for improved empirical quantification of the environmental drivers of wildfire spread and their control on ROS at landscape-scales during extreme wildfire events (EWE) [20-24]. Better understanding and near real-time estimation of wildfire ROS frequency distributions at landscape-scales could help fire scientists, managers, and emergency responders focus future research, evacuation, suppression, and mitigation efforts [19,25-28]. 
Although interactions between the land surface, lower atmosphere, and fire spread are complex, amalgamations of (1) fuel, (2) topographic, and (3) weather or fire-induced weather properties are widely recognized as being dominant influences on fire spread [29-33]. Wildland fire fuels are characterized by vegetation's biophysical characteristics such as surface area-to-volume ratio, load (mass per unit area), spatial distribution (horizontal and vertical structure), bulk density (mass per unit volume), and moisture content [34-37]. Fuel characteristics are difficult to quantify across time and space [37], but many researchers have found success using remotely sensed image data to characterize vegetation composition, which is used to represent the structural components of fuels [35-39]. When investigating relationships between wildfire behavior and fuels, researchers commonly classify vegetation types to generate fuel maps using a combination of image processing, manual image interpretation, and ground-survey data $[35,39,40]$. Vegetation growth forms (GF) (sometimes called life forms) are the conglomeration of plant species based on their similarities in growth function, physical structure, and life cycle [41]. Image-derived spectral vegetation indices (SVIs) can also serve as surrogates of fuel characteristics and are often used as input to image classification routines for mapping fuels [38-40]. For example, the Normalized Difference Vegetation Index (NDVI) is one of the most studied and utilized SVIs for estimating fuel physiological and morphological characteristics. NDVI has been correlated to shrub height [42], shrub biomass [43], shrub live fuel moisture content [44], and leaf area index (LAI) [45].

Topography, particularly slope angle in the relative direction of forward fire progression, is another landscape feature that influences wildfire spread [5-7,29]. Slope aspect, orientation (i.e., up- or downslope in direction of fire spread), and angle also indirectly affect fuel conditions and weather, which in turn control ROS [46-48]. A fire burning upslope can be very intense and fast-moving, where the opposite is documented for fires spreading downslope or across flat terrain, particularly in low wind conditions [5,49-51]. Quantitative characterizations of topographic slope and ROS relationships have been largely limited to laboratory and outdoor experiments or computational fire spread models [4,5,49-52]. Subsequently, many models that are operationally employed around the world inadequately represent or ignore downhill slope effects on ROS [52]. Remote sensing and simulation studies investigating topographic controls on wildfire behavior generally use digital elevation model (DEM) data to characterize slope for statistical stratification [53], fire severity [54], and predicting fire risk [55].

Weather during extreme wildfire events and antecedent precipitation affect ROS [2,29-32]. Methods used to evaluate the influence of weather (particularly wind speed, and relative humidity) on ROS have been conducted using laboratory and outdoor fire experiments, model simulations, climate record modeling, and anecdotal observations $[10,30,56-58]$. Studies investigating the influence of climate-scale factors vs. day-to-day weather on extreme wildfire behavior are conflicting, and even under ideal fire conditions, most spreading occurs over small proportions of an extreme event's life cycle $[58,59]$. Due to the issues related to reproducibility (compared to laboratory experiments) regional statistical analyses on climatic influences on extreme wildfire events are most common $[60,61]$. Similarly, because weather is regarded as the "wildcard" of fire spread [32], some researchers isolate wind variables in their research to investigate other environmental components, namely fuels and topography e.g., [7,46,53].

Though ROS is a key characteristic of fire behavior, it is difficult to measure during extreme wildfire events. However, airborne thermal-infrared (ATIR) imaging systems enable researchers and fire behavior analysts who support incident commanders to collect data and information on wildfire spread at relatively high spatial and temporal resolutions [62-65]. ATIR imaging has traditionally been used to map and monitor changes in fire perimeters [66], evaluate energy release by intensity [67-69], and measure spread direction and residence time [62-64]. When ATIR systems are utilized for repetitive and coordinated imaging missions localized to active fire fronts, the resultant thermal imagery can be used to precisely estimate fire rates of spread and directions $[63,64]$. Viedma et al. [54] is one of 
the few studies besides our own that used relatively high spatial resolution remotely sensed data to empirically analyze ROS during an extreme wildfire event. They estimated ROS from time-sequential fire perimeters delineated from ortho-rectified aerial photographs during the Riba de Saelices fire in Spain and used ROS as a covariate (among many others) for predicting burn severity. Storey et al. [70] used ATIR imagery to statistically analyze spotting behaviors during several large fires in Australia, however their work was focused on analyzing spotting occurrences rather than full fire spread runs.

Repetitive-ATIR imagery collected over several recent California wildfires, made it possible to map active fire front locations and estimate fire rates of spread at high levels of spatial and temporal detail. We statistically examined landscape-scale controls on fire spread rates collected from several chaparral and oak woodland landscapes based on a statistical-empirical approach utilizing ATIR image sequences, high spatial resolution optical imagery, and DEMs. Landscape covariate relationships with ROS estimates were analyzed with regression. Within the context of primarily canopy fire spread in shrubland vegetation, the following research questions are addressed:

1. How effective are spectral vegetation indices (SVIs) and fractional cover of growth form types, derived from high spatial resolution aerial orthoimages, as spatially explicit surrogates for fuel load distributions, in predicting ROS?

2. How strongly associated are directional slope angle and slope orientation relative to fire spread direction with ROS?

\section{Materials and Methods}

\subsection{Study Areas}

Study areas for this research correspond to the spatial coverage of sequential ATIR imagery captured during the Detwiler and Thomas Fire events in California, as illustrated in Figure 1. The Detwiler Fire burned over 30,000 ha of Sierra Nevada foothills in Mariposa County from 16 July through 9 January 2018 [3]. The Thomas Fire burned from 4 December 2017 to 12 January 2018, in Santa Barbara and Ventura counties [3]. It is the second largest recorded fire (single ignition source) in California history, burning over 113,000 total hectares across generally rugged mountainous terrain. The study areas are composed of chaparral, coastal sage scrub, oak woodland, and mid-elevation coniferous forest ecosystems.
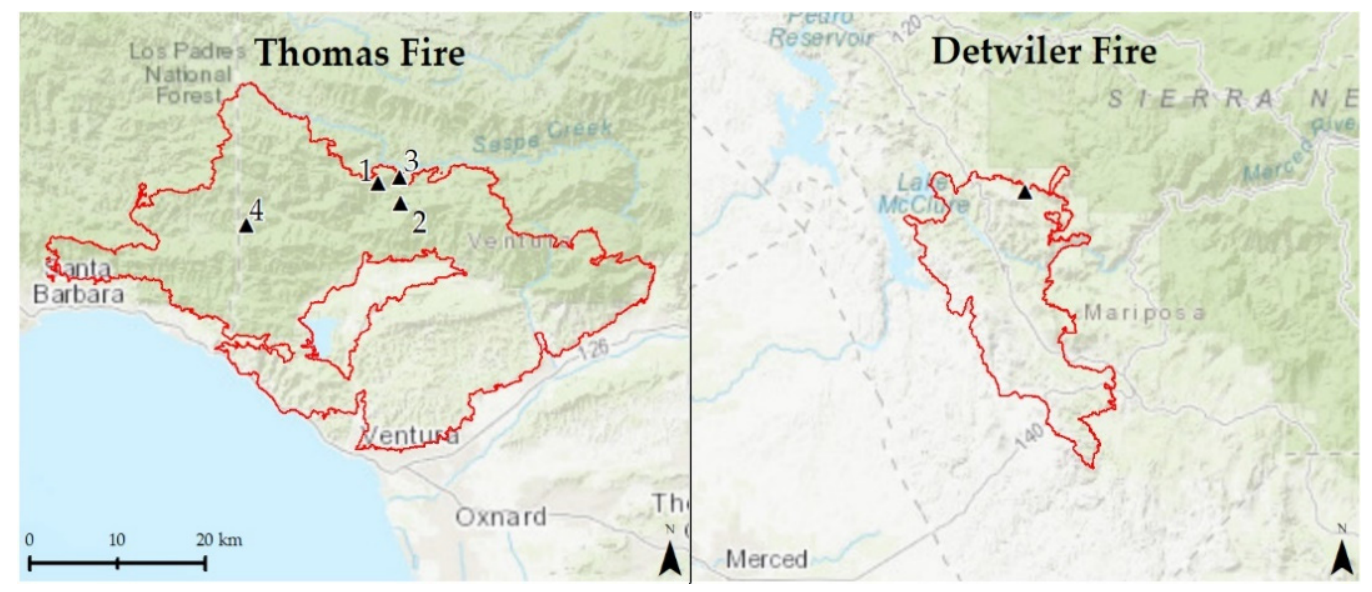

Figure 1. Two study wildfires in California. Map shows general burn externs of 2017 Detwiler and Thomas Fires. Numbers depict locations of airborne thermal infrared imaging sequences within burn extents (see Table 1). 
Altogether, the study areas exhibited a wide range of vegetation species, but were predominately composed of Chamise (Adenostoma fasciculatum), Buckbrush Ceanothus (Ceanothus cuneatus), California Scrub Oak (Quercus beridifolia), Canyon Live Oak (Quercus chrysolepsis), Interior Live Oak (Quercus wislizeni), Whiteleaf Manzanita (Arctostaphylos viscida), and California Oatgrass (Danthonia californica).

The study areas are characterized by moderate Mediterranean climate regimes typical of much of the Southern California region. Hot and dry summers are succeeded by mild wet winter with average annual precipitation ranging from 32 to $53 \mathrm{~cm}$. Both study areas were delineated and analyzed using the Universal Transverse Mercator (UTM) coordinate system-zones 10 and 11 north.

\subsection{Data}

ATIR imagery collected by Kolob Canyon Air Services using a FireMapper ${ }^{\mathrm{TM}} 2.0$ thermal infrared imaging system was used for ROS measurements for both study fires. FireMapper ${ }^{\mathrm{TM}} 2.0$ is a noncryogenic sensor with a $320 \times 240$ frame array [64,71]. The imagery was captured in short-, mid-, and long-wave infrared wavelengths, yielding images with 5-15 m ground sample distance (GSD) depending on flight altitude above ground level [71]. The long-wave TIR imagery was utilized in this study. Imagery was acquired over the same fire front with a "race-track" pattern as described in Stow et al. [64]. All images include a GPS location and time stamp that provides each frame with temporal and geographic coordinate metadata. FireMapper imagery was geometrically corrected with ERDAS IMAGINE Photogrammetry Software Application [72] using onboard positional (GPS) and altitude (inertial motion unit) data to yield georeferenced image frames. Stow et al. [64] found that the coregistration of sequential pairs of geoprocessed FireMapper ${ }^{\mathrm{TM}}$ 2.0 imagery to be approximately one-pixel root mean square error. ATIR image sequences were prioritized for ROS analyses based on a high number of repetitive, short-interval ( $<12 \mathrm{~min}$ ) flight-passes over active fire fronts burning within varied topography (different angles and orientations of slope facets during front progression) to sample a range of fire spread dynamics. ATIR observations analyzed in this research pertain to samples of maximum forward fire spread. A summary of ATIR image metadata for the sequences analyzed in this research is shown in Table 1.

Table 1. Airborne thermal infrared imagery metadata by study fire and image sequence.

\begin{tabular}{|c|c|c|c|c|c|c|}
\hline Sequence & Date & Time-Range (Local) & Passes & $\begin{array}{c}\text { Frames/ } \\
\text { Pass }\end{array}$ & $\begin{array}{c}\text { Ave. Time bet. } \\
\text { Successive Passes (min) }\end{array}$ & $\begin{array}{l}\text { GSD } \\
(\mathrm{m})\end{array}$ \\
\hline Detwiler & Thursday, 20 July 2017 & 3:24:57 to $4: 13: 30$ p.m. & 7 & 25 & $8: 07$ & 13 \\
\hline Thomas 1 & Friday, 8 December 2017 & 2:23:12 to $5: 36: 11$ p.m. & 23 & $30-90$ & $10: 09$ & 10 \\
\hline Thomas 2 & Friday, 8 December 2017 & 2:22:54 to $5: 46: 11$ p.m. & 26 & $30-90$ & $8: 24$ & 10 \\
\hline Thomas 3 & Friday, 8 December 2017 & 4:29:49 to $5: 12: 19$ p.m. & 7 & $15-30$ & $7: 05$ & 10 \\
\hline Thomas 4 & Saturday, 9 December 2017 & 4:33:44 to $5: 22: 48$ p.m. & 9 & $30-35$ & $6: 08$ & 10 \\
\hline
\end{tabular}

Prefire visible/near infrared aerial imagery from the National Agricultural Inventory Program (NAIP) was obtained from USGS Earth Explorer (https:/ / earthexplorer.usgs. gov /) and Google Earth Engine (GEE) [73] to map and quantify fuel characteristics. The NAIP image sets were captured between July and August 2016, and consist of $0.6 \mathrm{~m}$ spatial resolution, four-band visible and near-infrared georeferenced orthoimages. Topographic data were derived from National Elevation Dataset (NED) $10 \mathrm{~m}$ spatial resolution digital elevation models (DEMs). These DEM data were obtained from the GEE data cloud.

Weather data were retrieved from the Remote Automated Weather Station (RAWS) online data library (https:/ / raws.dri.edu/wraws/scaF.html) and from the FireBuster model Thomas and Detwiler fire forecasts [74]. FireBuster is a fire weather forecast system that provides spatially explicit weather estimates based on downscaled weather model and digital terrain data inputs and are available through an interactive webtool or downloadable $1 \mathrm{~km}$ raster grids (https://fwxfcst.us/firebuster/) [74]. The RAWS data and FireBuster 
estimates obtained for this study consisted of hourly wind speed average, wind speed max, wind direction, and relative humidity estimates nearest to the space/time domain of the study areas and ATIR image collection times. Distances from RAWS to study areas ranged from a minimum of $5.5 \mathrm{~km}$ (Thomas 1, 2, and 3) to a max of $13.3 \mathrm{~km}$ (Detwiler).

\subsection{Fire Feature Delineation and Landscape Sampling Units}

Fire fronts were delineated from ATIR imagery using methodologies developed by Stow et al. [63,64] (Figure 2a). ATIR imagery was contrast enhanced to aid in active fire front detection and delineation. Images influenced by large amounts of smoke and hot gases were processed using a Laplacian edge filter to enhance fire front locations and aid in their delineation. ArcGIS Pro ver. 2.5.0 [75] software tools were used to interactively delineate fire front line curves in the form of polyline features that contain attribute information associated to the front length (m), front ID, and time of ATIR image capture. Fire fronts were manually delineated in ATIR imagery by drawing polylines at the sharpest radiometric temperature descent (i.e., gradient between fire and non-fire (ambient) temperatures) (Figure 2a).

(a)

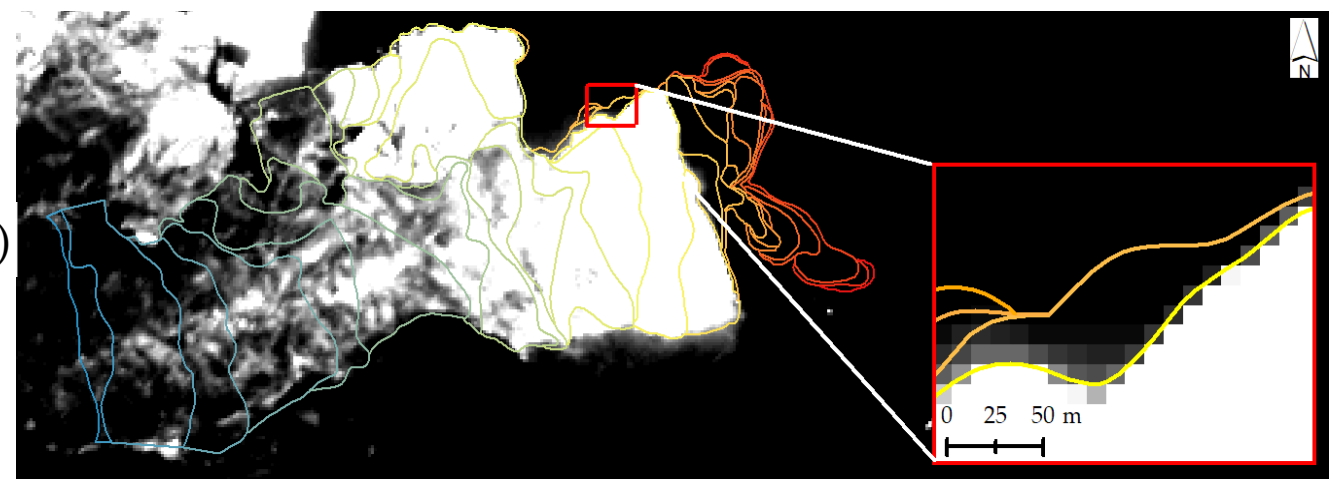

(b)
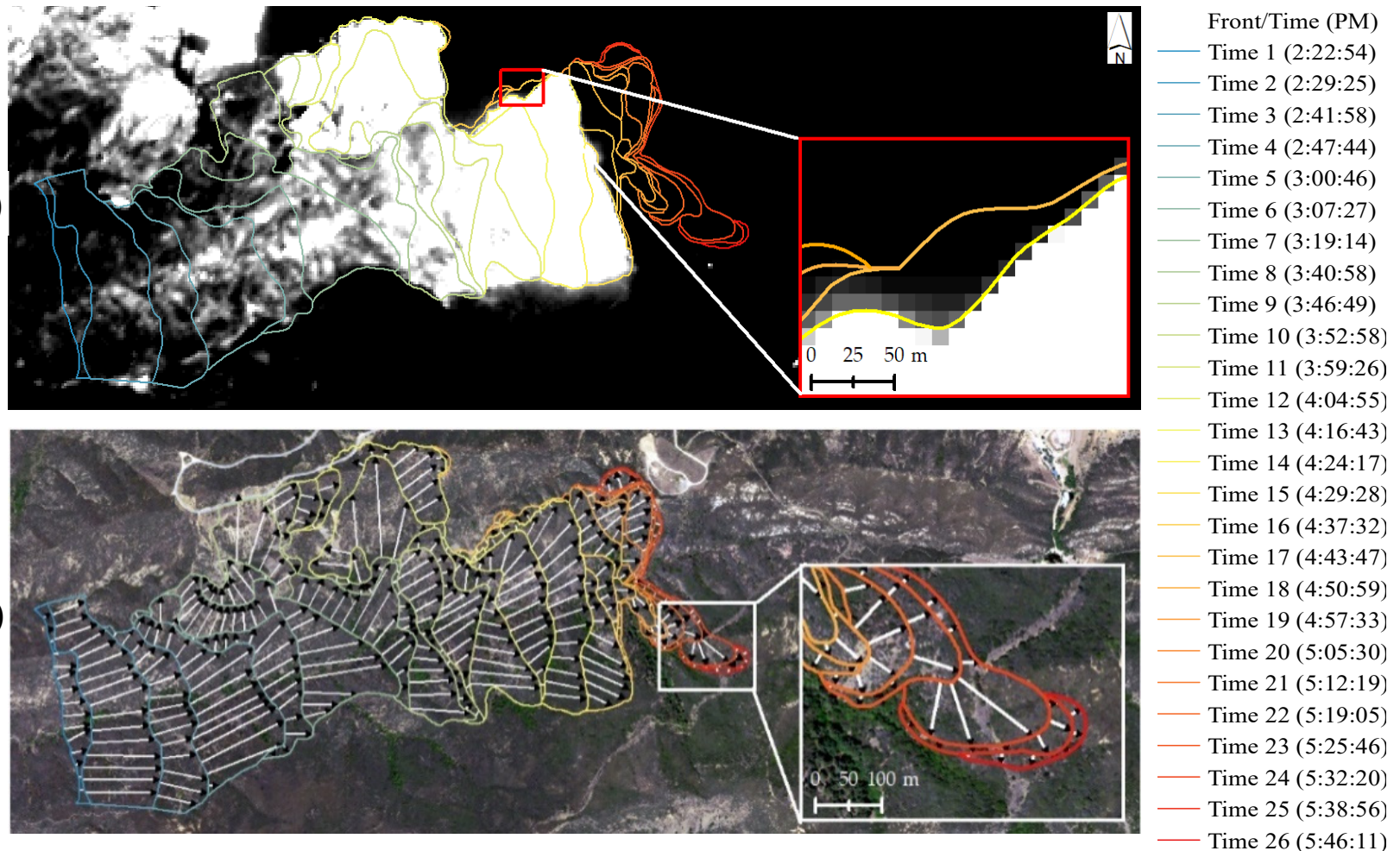

Figure 2. Fire front delineation and fire spread vector/LSUs for Thomas Sequence 2. (a) Fire fronts overlaid on contrastenhanced pass-15 thermal infrared (TIR) image. Inset map depicts from location relative to TIR pixel gradient; (b) fire spread vectors and LSUs with fire fronts overlaid on National Agriculture Imagery Program (NAIP) orthoimagery. The average time between successive fire fronts for Thomas 2 was 8:24 ( $\mathrm{min})$.

Fire spread-vectors were represented as linear features connecting sequential fire fronts and their origin, spacing, and direction was identified on a sequence-by-sequence basis [64]. Evenly spaced $(30 \mathrm{~m})$ [64] points along a time $=\mathrm{n}$ (start) front curve were automatically generated by local-normal polyline connections from each point to the intersection of the time $=\mathrm{n}+1$ fire front (Figure $2 \mathrm{~b}$ ). Spread vectors were assigned geometry attributes including line bearing $\left(0-360^{\circ}\right)$, distance $(\mathrm{m})$, and ROS estimate $\left(\mathrm{m} \mathrm{min}^{-1}\right)$. Fire spread vectors were also used as landscape sampling units (LSUs) for extracting topographic and fuel data for subsequent statistical analyses. 


\subsection{Orthoimage Processing}

Three spectral vegetation indices (SVIs) were generated from NAIP orthoimages and tested as fuel loading covariates with ROS. NAIP imagery utilized in this study were not calibrated to surface reflectance values. Normalized Difference Vegetation Index (NDVI-U) (Equation (1)), Green-Red Vegetation Index (GRVI-U) (Equation (2)), and Normalized Difference Red-Blue (NDRB-U) (Equation (3)) images were created for all fire sequences based on the following formulae:

$$
\begin{gathered}
\text { NDVI-U }=\frac{(\text { NIR }- \text { RED })}{(\text { NIR }+ \text { RED })} \\
\text { GRVI-U }=\frac{(\text { GREEN }- \text { RED })}{(\text { GREEN }+ \text { RED })} \\
\text { NDRB-U }=\frac{(\text { RED }- \text { BLUE })}{(\text { RED }+ \text { BLUE })}
\end{gathered}
$$

where in Equations (1)-(3), -U represents uncalibrated to surface reflectance, NIR, RED, GREEN, and BLUE are uncalibrated (surface reflectance) NAIP digital number values for near-infrared, red, green, and blue wavebands, respectively. These SVIs were selected because they exploit different waveband combinations associated with the NAIP data, and normalized indices tend to suppress terrain-related illumination and image brightness effects [76]. NAIP imagery was also used to classify and map vegetation GF types as surrogates for fuel load. Input data for classification started with generating a false-color composite image of NDVI-U (Equation (1)), Visible Brightness (VB) (Equation (4)), and the red/green band ratio (RG) (Equation (5)) [77].

$$
\begin{gathered}
\mathrm{VB}=(\text { RED }+ \text { GREEN }+ \text { BLUE }) \\
\text { RG }=\text { RED } / \text { GREEN }
\end{gathered}
$$

where RED, GREEN, and BLUE are uncalibrated NAIP digital number values for red, green and blue wavebands, respectively. NDVI-U, VB, RG thresholds were established interactively for classifying the following GF and land cover classes: (1) shrub, (2) herb, (3) tree, and (4) rock/bare soil. Map accuracy was assessed by comparing classification products with reference data generated from visual interpretation of 100 randomly sampled NAIP pixels and prefire Google Earth imagery. The overall accuracy of image classification products was $91 \%$. Misclassified GF pixels identified during accuracy assessment were manually edited and recoded. Polygons were drawn around misclassified pixels and reclassified to reflect the correct GF type visually observed in reference imagery. Reclassification was followed by reconducting accuracy assessment and the procedure was repeated until an accurate map was produced.

\subsection{Topographic Data Processing}

Slope angle and orientation (relative to fire spread direction) were assessed as landscape topographic covariates with ROS. Standard slope functions found in GIS software lack the ability to generate nonstatic directional slope (i.e., relative slope in a predefined direction). To overcome this, we developed a DEM processing routine with Python ver. 3.0.2 and the RichDEM terrain analysis library [78] designed to measure the slope inclination relative to the fire spread direction associated with spread vector bearings. Slope-degree, slope-aspect, and fire-direction (bearing direction of vector) rasters were calculated for each LSU [79]. The slope angle and aspect, and fire-direction rasters for each LSU were then computed and processed into the directional slope covariate using Equation (6):

$$
\mathrm{DS}=\mathrm{S} * \cos \left((\mathrm{VD}-\mathrm{A}) * \frac{\pi}{180}\right) *-1
$$


where DS is the output directional slope raster, $\mathrm{S}$ is a raster grid representing slope degree values, VD is the spread vector bearing (degree) raster, and A is the aspect in degrees. The output represents slope angle as a signed degree slope, where negative (downhill) and positive (uphill) values are calculated relative to the spread vector directions. Rasters having $0^{\circ}$ values signify flat slopes.

\subsection{Landscape Covariate Sampling and Stratification}

Zonal sampling, validation, and organization of covariate data were conducted using R v.3.6.2 and ArcGIS scripting and software tools and organized as a relational database using PostgreSQL ver. 9.6.2. LSUs were created spatially coincident to spread vector using the "Buffer" tool in ArcGIS Pro. Like the spread vectors, LSUs were assigned spatial geometry attributes consisting of the fire spread bearing, the length of the unit, and the unit's size $\left(\mathrm{m}^{2}\right)$. The LSUs constituted the basis for automatically extracting topographic and fuel data for subsequent statistical analyses. LSU buffers were created to capture DEM and NAIP pixels spatially coincident to spread vector polylines. The mean, minimum, maximum, range, standard deviation, median, and variance of directional slope and SVI pixels were extracted for each LSU using the R "exactextractr" package [80].

GF fractional cover (GFFC) estimates for LSUs were calculated with a raster model that converts like-classified, contiguous GF pixels into polygons. The GFFC percentage of each LSU was quantified on a scale of 0.0-1.0. GFFC estimates were also used to assign a "LSU Fuel Class" type to each sample unit (Table 2 a), based on combinations of fuel/vegetation classification schemes derived from prior studies including Anderson [34], Sandberg et al. [81], and Blodgett et al. [53]. GFFC were stratified into one of two separate slope orientation groups: Slope angle $>0^{\circ}$ (upslope), Slope angle $<0^{\circ}$ (downslope) based on the mean directional slope (Table $2 \mathrm{~b}$ ). Google Earth was used to visualize 3-D topography and remove from statistical analyses LSUs associated with spread vectors where fire spread both up- and downslope between imaging passes. In total, 195 LSUs were removed from analyses for this reason. Samples of GFFC were stratified according to Table $2 \mathrm{~b}$ and regressed. Directional slope angles from all sample units were paired with fuel classes according to Table $2 \mathrm{c}$ and regressed. Directional slope samples were also stratified and regressed by orientation (upslope and downslope).

Table 2. Explanatory variable classification and stratification schemes. (a) Growth form fractional cover estimates classification procedure (LSU fuel classes); (b) growth form fractions stratified by slope orientation; (c) slope angle means stratified by fuels.

\begin{tabular}{ccccc}
\hline \multicolumn{2}{c}{ a. LSU Fuel Classes } & \multicolumn{2}{c}{ b. GFs Stratified by Slope Angle } & \multicolumn{2}{c}{ c. Slope Stratified by Fuels } \\
\hline FC Estimate & Fuel Class & Growth Form & Slope $^{\circ}$ & Slope $^{\circ}$ \\
$\geq 75 \%$ Shrub & Shrub & & LSU slope angle \\
mean w $/:$ & Shrub \\
$\geq 75 \%$ Herb & Herb & $\%$ Shrub & w/slope angle $>0^{\circ}$ & Herb \\
$\geq 75 \%$ Tree & Tree & $\%$ Herb & Tree \\
$\geq 75 \%$ Rock/Bare Soil & Rock/Bare Soil & $\%$ Tree & w/slope angle $<0^{\circ}$ & Rock/Bare Soil \\
$\geq 50 \%<75 \%$ n cover & $n$-dominated Mix & $\%$ Rock/Bare Soil & & $n$-dominated Mix \\
$<50 \%$ cover dominance & Full Mix & & & Full Mix \\
\hline
\end{tabular}

\subsection{Statistical Analyses}

Several statistical models were employed to examine relationships between both stratified and unstratified landscape covariates and ROS estimates. These included: (1) bivariate linear regression, (2) multiple-stepwise linear regression, (3) power (log-log) regression, and (4) exponential (semi-log) regression. All models were fit and analyzed using $\mathrm{R}$ ver. 3.6.2 [82]. 
Exploratory data analyses of ROS estimates and landscape covariates were conducted to summarize data quality, distribution, and covariance [83]. Sample means, variances, minima, maxima, standard deviations, kurtosis, skewness, and correlation statistics were used to evaluate all landscape covariates separately, and cumulatively. Independent variables that exhibited significant control on ROS estimates were initially evaluated using parametric and nonparametric difference-of-means/median tests, including: two sample t-test, Wilcoxon rank sum, analysis of variance (ANOVA), and Kruskal-Wallis tests [83,84].

Bivariate linear regression models evaluated direct relationships between individual landscape covariates and ROS estimates, for each spread sequence and covariate (stratified and unstratified). All bivariate models were evaluated and compared using beta coefficients, standardized beta coefficients, adjusted coefficient of determination (adj. $R^{2}$ ), Akaike's Information Criterion (AIC), and $p$-value diagnostics [83,85].

Multiple linear regressions were run to determine the cumulative influence and interaction of covariates on ROS estimates. Forward- and backward-stepwise regression models were constructed using the lowest AIC, lowest Mallows $C P$, highest adj. $\mathrm{R}^{2}$, and significant F-statistic [83]. All ordinary least squares (OLS) models were evaluated using ANOVA tests to check whether they were statistically significant or not through corresponding $F$ and $p$-values [85]. Standardized coefficients of parameter estimates were also evaluated to determine the direct influence of individual covariate estimates. Covariates in multiple regression models were also tested for multicollinearity using the variance inflation factor (VIF) [86]. Multiple regression models were fit with all landscape covariates minus one GF type. One GF type at a time was removed from multiple regression models using hierarchical partitioning to clear the compositional nature of GFFC estimates [87]. The removal of any growth form variable was determined on a sequence-by-sequence basis using regression goodness-of-fit diagnostics derived from the heir.part $R$ package (Adj. $R^{2}$, Log-Likelihood, and root mean square error) [88] as precursors for candidacy in multiple regression models.

Throughout the OLS modeling process, we looked for violations of model assumptions and if found, data log-transformations and/or different techniques were used to model relationships. First, plots were used to validate assumptions of normality, linearity, and equity of variances [83]. Residual Quantile-Quantile (QQ) plots were used as an initial test for residual normality. To confirm QQ-plot visualizations the Shapiro-Wilk test [83] was performed to test residual normality. Residuals were also plotted against predicted ROS $(y)$ values to determine any residual clustering or obvious patterns that indicated violation of model assumptions [83].

\section{Results}

\subsection{Fire Spread Behavior}

Maps of fire front progressions for each fire spread sequence are shown in Figure 3. Frequency plots of ROS estimates with rose plots of fire spread direction frequency for the five sequences are presented in Figure 4. Although fire spread rates varied substantially within and between ATIR sequences, all sample distributions are comparably right-skewed with mean rates of spread greater than the median. Median rates of spread ranged from a low of $4.2 \mathrm{~m} \mathrm{~min}^{-1}$ (Detwiler) to a high of $12.7 \mathrm{~m} \mathrm{~min}^{-1}$ (Thomas 4). The maximum ROS estimate for each sequence are 27.9, 57.0, 64.9, 30.9, and $142.1 \mathrm{~m} \mathrm{~min}^{-1}$ for Detwiler, Thomas 1, Thomas 2, Thomas 3, and Thomas 4, respectively. The Detwiler sequence, characterized by predominantly downslope fire spread, exhibits the lowest spread estimate of $0.2 \mathrm{~m} \mathrm{~min}^{-1}$ and lowest group median of $4.2 \mathrm{~m} \mathrm{~min}^{-1}$. Fire spread directions for Detwiler were localized to the north, northeast, and east (Figure 4a). Thomas 1 and 2 depict fire movement along the same perimeter edge but are separated by a large ridge. Fire spread for Thomas 1 and 2 occurred mainly upslope with comparable median ROS of 9.0 and $7.8 \mathrm{~m} \mathrm{~min}^{-1}$, respectively; fire spread mostly to the north and east (Figure $4 \mathrm{~b}, \mathrm{c}$ ). Thomas sequence 3 imagery captured a backing fire ignited by CalFire responders at nearly the same time and within the vicinity of Thomas 1 and 2. The median ROS for Thomas 3 
is $5.0 \mathrm{~m} \mathrm{~min}^{-1}$ and spread directions are to the north, south, and northwest (Figure $4 \mathrm{~d}$ ). The highest maximum $\left(142.1 \mathrm{~m} \mathrm{~min}^{-1}\right)$ and median $\left(12.7 \mathrm{~m} \mathrm{~min}^{-1}\right)$ ROS are captured in Thomas sequence 4 (Figure 4e). Fire spread for Thomas 4 occurred primarily to the west and southwest, driven by east-northeasterly Santa Ana wind conditions (Figure 4e).

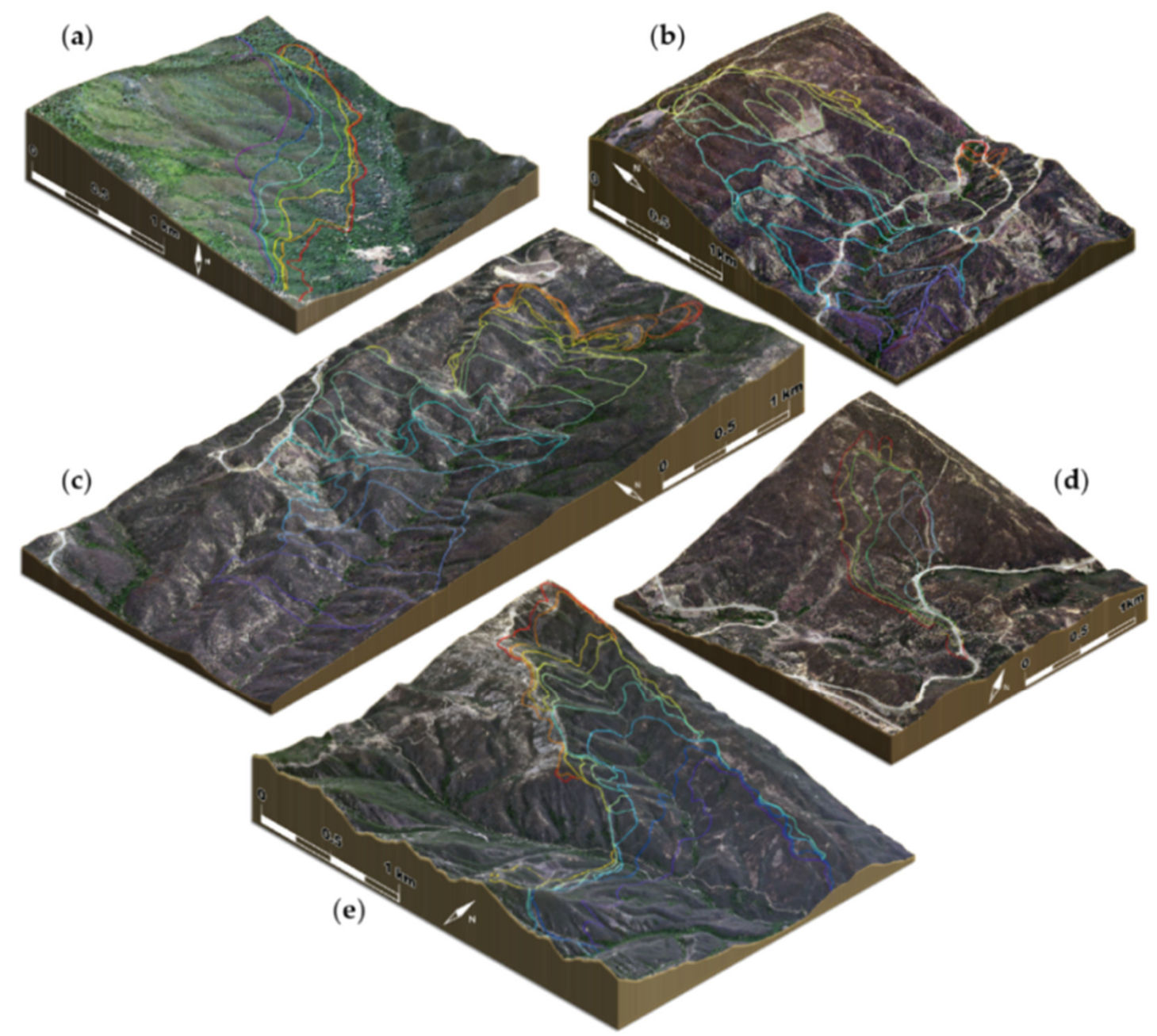

Figure 3. Airborne thermal infrared fire spread sequences overlaid on 3D terrain models. Progression of color spectrum depicts movement of fire fronts over time. (a) Detwiler; (b) Thomas 1; (c) Thomas 2; (d) Thomas 3; (e) Thomas 4. The average times between successive fire front positions (min) are 8:07 (Detwiler), 10:09 (Thomas 1), 8:24 (Thomas 2), 7:05 (Thomas 3), and 6:08 (Thomas 4). 
(a)

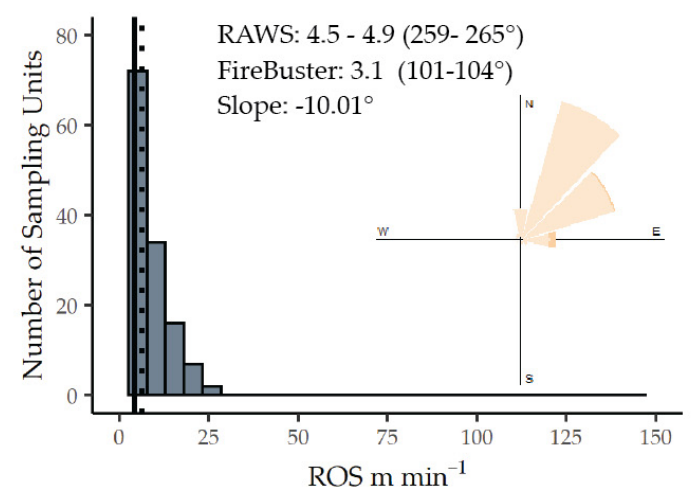

(c)

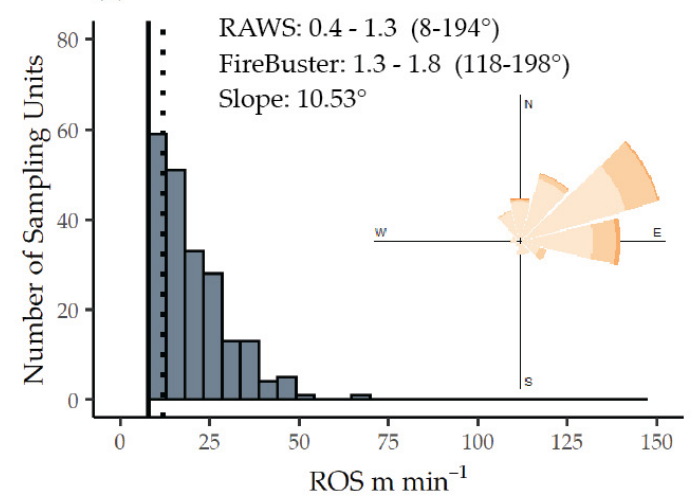

(e)

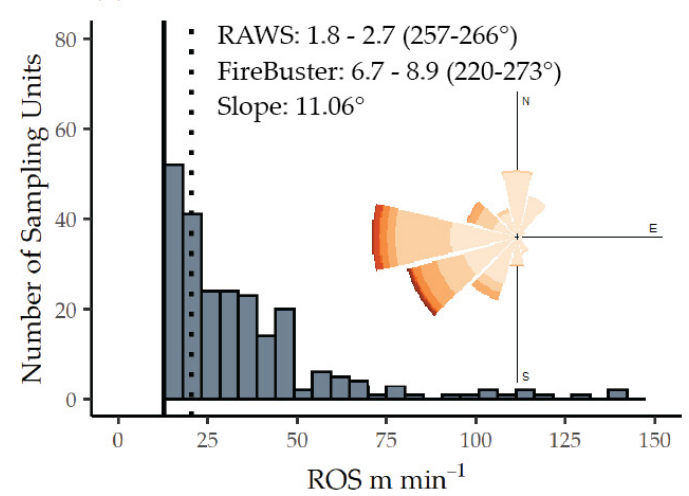

(b)

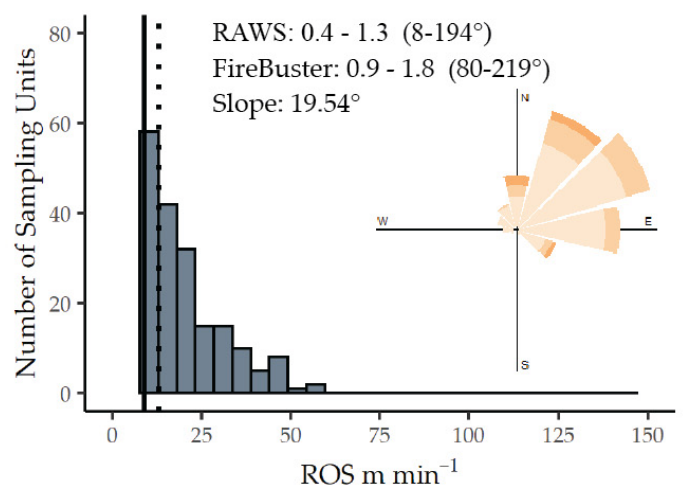

(d)

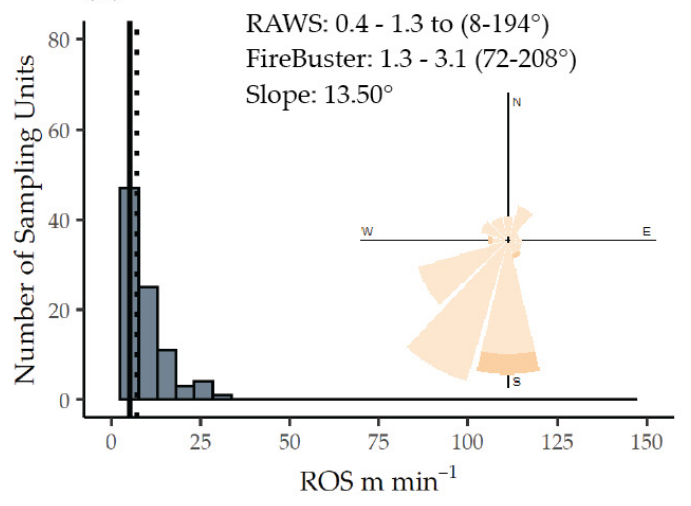

Mean:.........

Median:

Rose plots (ROS $\left.\mathrm{m} \mathrm{min}^{-1}\right)$ :

$0-20 \quad 20-40 \quad 40-60 \quad 60-80 \quad 80-100100-120 \quad 120+$

Figure 4. Fire spread rate sample frequency histograms and rose plots of sample spread frequency by rate of spread with Remote Access Weather Station (RAWS) and FireBuster wind speeds ( $\mathrm{m} \mathrm{s}^{-1}$ ) and wind direction (deg) ranges during airborne thermal infrared imaging. Generalized slope trend for sequences are also included. (a) Detwiler. (b) Thomas 1. (c) Thomas 2. (d) Thomas 3. (e) Thomas 4.

\subsection{Wind Conditions During Fire Sequences}

RAWS data and FireBuster predictions associated with ATIR collection areas and periods are summarized in Table 3 . The lowest recorded wind speeds were reported during Thomas 1, 2, and $3(0.4 \mathrm{~m} / \mathrm{s}$ NNW). FireBuster wind speed predictions for Thomas 1, 2 and 3 are on average $0.77 \mathrm{~m} \mathrm{~s}^{-1}$ faster than RAWS measurements. Wind direction (RAWS) for Thomas 1 and 2 range were S-SSW during the first $1.5 \mathrm{~h}$ of spread, and NNW for the remainder of the sequences. The fastest wind speed $\left(8.9 \mathrm{~m} \mathrm{~s}^{-1}\right)$ and lowest average reported relative humidity $(12.7 \%)$ was reported during Thomas 4 . Detwiler wind speeds during ATIR imaging ranged from 4.5 to $4.9 \mathrm{~m} \mathrm{~s}^{-1}$ (RAWS) and $3.1 \mathrm{~m} \mathrm{~s}^{-1}$ (FireBuster). Wind direction reported from RAWS nearest to Detwiler $(13.3 \mathrm{~km})$ exhibit NNE winds. 
FireBuster predictions for Detwiler record WNW winds. Relative humidity for the Detwiler sequence was 23-24\% (RAWS) and 14.8-16.3\% (FireBuster). Overall, wind speed, wind direction, and relative humidity data and predictions from RAWS and FireBuster forecasts varied little over the time domain of all sequences.

Table 3. Remote Access Weather Station (RAWS) and FireBuster weather reports by fire and rate of spread (ROS) sequence. Weather attributes depict data range reported during airborne thermal infrared (ATIR) image collection periods. The elapsed time of ATIR imaging is included in sequence headings. Average reported ROS derived from landscape sampling units.

\begin{tabular}{|c|c|c|c|c|c|}
\hline $\begin{array}{c}\text { Sequence } \\
\text { (HH:MM:SS) }\end{array}$ & Source & $\begin{array}{l}\text { Wind Speed } \\
\qquad\left(\mathrm{m} \mathrm{s}^{-1}\right)\end{array}$ & $\begin{array}{l}\text { Wind Direction } \\
\text { (Vector) }\end{array}$ & $\begin{array}{c}\text { Relative } \\
\text { Humidity (\%) }\end{array}$ & $\begin{array}{l}\text { Average ROS } \\
(\mathrm{m} \mathrm{min}-1)\end{array}$ \\
\hline Detwiler (0:48:33) & $\begin{array}{c}\text { RAWS: } \\
\text { FireBuster: }\end{array}$ & $\begin{array}{c}4.5-4.9 \\
3.1\end{array}$ & $\begin{array}{l}259-265 \\
101-104\end{array}$ & $\begin{array}{c}23-24 \\
14.8-16.3\end{array}$ & 6.23 \\
\hline Thomas 1 (3:12:59) & $\begin{array}{c}\text { RAWS: } \\
\text { FireBuster: }\end{array}$ & $\begin{array}{l}0.4-1.3 \\
0.9-1.8\end{array}$ & $\begin{array}{c}8-194 \\
80-219\end{array}$ & $\begin{array}{c}7-18 \\
10.5-30.2\end{array}$ & 12.86 \\
\hline Thomas 2 (3:23:17) & $\begin{array}{l}\text { RAWS: } \\
\text { FireBuster: }\end{array}$ & $\begin{array}{l}0.4-1.3 \\
1.3-1.8\end{array}$ & $\begin{array}{c}8-194 \\
118-198\end{array}$ & $\begin{array}{c}7-18 \\
10.5-28.6\end{array}$ & 11.84 \\
\hline Thomas 3 (0:42:30) & $\begin{array}{c}\text { RAWS: } \\
\text { FireBuster: }\end{array}$ & $\begin{array}{l}0.4-1.3 \\
1.3-3.1\end{array}$ & $\begin{array}{c}8-194 \\
73-208\end{array}$ & $\begin{array}{c}7-18 \\
8-71.9\end{array}$ & 7.05 \\
\hline Thomas 4 (0:49:04) & $\begin{array}{c}\text { RAWS: } \\
\text { FireBuster: }\end{array}$ & $\begin{array}{l}1.8-2.7 \\
6.7-8.9\end{array}$ & $\begin{array}{l}257-266 \\
220-273\end{array}$ & $\begin{array}{c}10-13 \\
7.3-16.1\end{array}$ & 20.37 \\
\hline
\end{tabular}

\subsection{Fuel Covariate Relationships with ROS}

Statistical models for exploring SVIs as spatially explicit surrogates for fuel load covariates for ROS yielded few significant correlations. Bivariate regression diagnostics by fire and ATIR sequence yielded very weak and mostly nonsignificant relationships. For the Detwiler and Thomas 4 sequences, all SVIs are statistically significant with ROS. Of the statistically significant SVI models, the maximum total explained variance is only $5.4 \%$ (NDVI-U, Thomas 4). Weak but significant SVI relationships for Detwiler and Thomas 4 are attributed to greater spatial variability in fuel coverage and type compared to other sequences. For the study areas (sequences) and SVIs examined in this research, SVIs alone were not effective predictors of ROS. Weak statistical relationships likely stem from limited spatial variability in fuel composition and density within the burning areas captured during ATIR imaging. GFFC distributions for the four Thomas fire sequences were largely characterized by homogenous, high density of chaparral shrubs. Although shrubs predominantly cover landscapes burned during the Thomas sequences, sparse cover of tree, rock/bare soil, and herbaceous vegetation types are observed, based on image-classification products. Notably, portions of Thomas 1, 2, and 4 sequences contained dense corridors of riparian vegetation along riverbeds cutting through the sequence extents. The diversity of GFs is greater for the Detwiler fire sequence compared to Thomas fire sequences. LSUs associated with the Detwiler sequence are characterized by similar shrub, herbaceous, and tree GFFC. The degree of model fit between GFs and ROS estimates is greater when samples containing zero percent fraction are removed from sample populations. Like SVIs, GFFC is weakly associated with fire spread rates. However, model coefficients and adj. $\mathrm{R}^{2}$ metrics indicate they were slightly more effective proxies for describing spatial distributions of fuel loads and control on ROS. For example, tree GFFC explained $36 \%$ and $12 \%$ of the total variation in ROS at Detwiler and Thomas 2, respectively. Similarly, rock/bare soil beta coefficients exhibit a negative relationship with ROS estimates at Detwiler, Thomas 1, and Thomas 2 (-14.53 to -23.45$)$, explaining $7-14 \%$ of the variance in ROS.

Stratifying GFFC samples by slope angle (upslope $>0^{\circ}$ and downslope $<0^{\circ}$ ) was largely ineffective at isolating contributions on ROS. Similar to SVI relationships with ROS estimates, weak association with GFFC (stratified and unstratified) may be attributed to limited spatial variation in prefire fuel composition within the burning areas captured by 
the ATIR image sequences. This observation is supported by the predominantly homogenous shrub cover portrayed in maps generated from prefire orthoimagery as depicted in Figure 5.

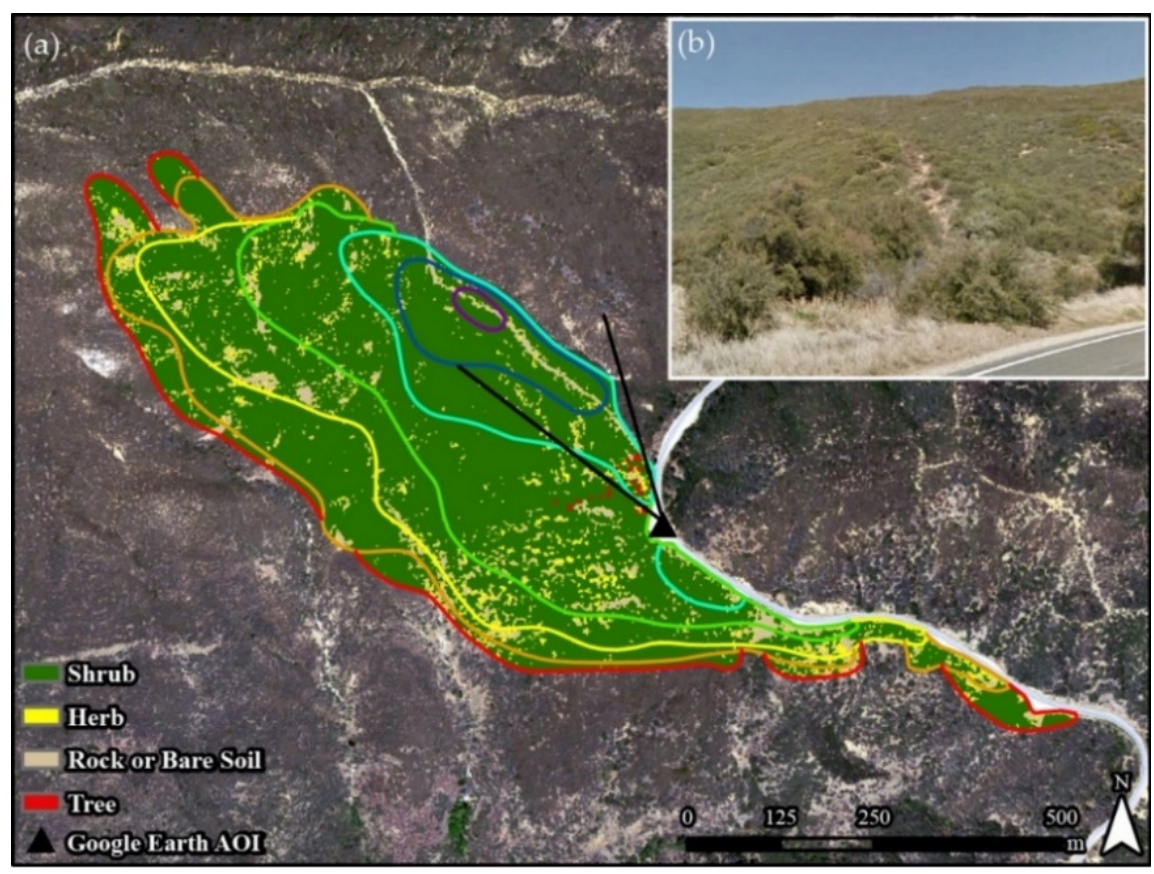

Figure 5. Thomas sequence 3 growth form composition. Figure depicts the largely homogenous fuel distribution at the Thomas Fire sampling areas. (a) Fire front positions overlaid on growth form map and National Agriculture Imagery Program (NAIP) orthoimagery. (b) Prefire Google Earth image overlooking portion of Thomas sequence 3 .

\subsection{Topographic Covariate Relationships with ROS}

Generalized trends of slope angle for entire image sequences of successive fronts are characterized by average upslope inclinations of $19.54^{\circ}, 10.53^{\circ}, 13.50^{\circ}$, and $11.06^{\circ}$ for Thomas 1, 2, 3, and 4, respectively (Figure 4). Fire progression for the Detwiler sequence primarily occurred downslope with an average decline of $-10.01^{\circ}$. Of all covariates examined, directional slope is the most statistically significant predictor of ROS estimates for all study fires and ATIR sequences. Linear, exponential, and power regression diagnostics on directional slope are reported in Table 4 . For Thomas sequences 1,2 , and 3 , about $50 \%$ of the variance of ROS estimates are explained by directional slope (adj. $R^{2} \geq 0.500$ ) (Table 4). Regression beta and standardized beta coefficients for all regression methods and study areas show positive linear to weakly nonlinear relationships between ROS and directional slope $(\beta>1)$. Scatter plots comparing linear, exponential, and power regression fits with directional slope data are shown in Figure 6.

Linear model coefficients are similar for Thomas sequences 1,2 , and 4 ( $\beta$ range of 0.066), while semi-log (exponential) regression coefficients are similar for Thomas 1, 2, and 3 ( $\beta$ range of 0.003). Exponential relationships for Detwiler and Thomas 4 exhibit similarity. Power regression models show similar degrees of variance explanation of ROS on directional slope as by exponential models (avg. adj. $\mathrm{R}^{2}$ difference of 0.010 ). Plots of ROS on directional slope data exhibit abrupt increases in ROS per incremental increase in slope angle at or around $20^{\circ}$ (Figure 6), confirming the strength of weakly nonlinear relationships exhibited by power and exponential regression metrics (Table 4). Comparable model fits between exponential and power regressions types are found for Thomas 1,2, and 3 (Figure $6 b-d$ ). Linear models for Detwiler (adj. $R^{2}=0.160$ ) and Thomas 4 (adj. $=R^{2} 0.194$ ) yielded higher model fit than exponential and power regression counterparts. Stronger linear regression fit for the Detwiler and Thomas 4 data are confirmed when comparing 
regression lines-of-best-fit (Figure 6a,e). Overall, exponential and power functions were most effective for characterizing the relationship between directional slope and ROS (adj. $\mathrm{R}^{2} \geq 0.500$ ), and consistently accounted for the steeper rise in spread rate commonly observed at slope angles of $20^{\circ}$ and greater.

All models stratified by upslope $\left(>0^{\circ}\right)$ and downslope $\left(<0^{\circ}\right)$ orientations are statistically significant. However, compared to nonstratified models, greater model fit only resulted for Detwiler and Thomas 4 (average adj. $R^{2}$ increase of 0.200). All upslope stratified models demonstrate markedly higher standardized and unstandardized beta coefficients. The opposite is true for downslope stratified groups. To minimize potential bias in slope findings incurred from samples having disparate GF types, slope samples were stratified by the LSU fuel classes shown in Table 2 c: (1) shrub, (2) mixed-shrub, (3) herb, (4) mixed-herb, (5) rock/bare soil, (6) mixed-rock/bare soil, (7) tree, (8) mixed-tree, and (9) full mix. All slope models stratified by the shrub and mixed-shrub fuel classes are statistically significant for all sequences. Minor increases in slope model fits occurred within the shrub and mixed-shrub classes for Thomas 1,2, and 3, while most $R^{2}$ values and coefficient estimates are comparable to nonstratified models. Slope stratified by the mixed-shrub fuel class yielded the highest model fit for Detwiler (adj. $R^{2}=0.422$ ) and Thomas 4 (adj. $\left.R^{2}=0.396\right)$. However, when slope data are stratified by other fuel classes, few models are significant. Detwiler was the only sequence where directional slope stratified by the herb fuel class was statistically significant (adj. $R^{2}=0.223, p=0.002$ ). Although the stratification of slope yielded few significant results for Thomas 1,2, and 3 (compared to unstratified models), increase in variance explanation for Detwiler and Thomas 4 were common.

Table 4. Linear, exponential (semi-log), and power (log-log) regression results and model equations for directional slope. Model diagnostics separated by fire and airborne thermal infrared image sequence.

\begin{tabular}{|c|c|c|c|c|c|}
\hline & \multicolumn{5}{|c|}{ Linear } \\
\hline & $\mathrm{n}$ & $\beta$ & $\mathrm{ROS}=\beta_{0}+\beta_{1} X_{i}$ & Adj. $R^{2}$ & $p$ \\
\hline Det. & 157 & 0.250 & $09.90+0.25$ (slope) & 0.160 & $<0.001$ \\
\hline Th 1. & 291 & 0.521 & $10.97+0.52$ (slope) & 0.413 & $<0.001$ \\
\hline Th 2 . & 372 & 0.459 & $10.85+0.46$ (slope) & 0.432 & $<0.001$ \\
\hline Th 3. & 123 & 0.292 & $08.18+0.29$ (slope) & 0.494 & $<0.001$ \\
\hline \multirow[t]{3}{*}{ Th 4.} & 332 & 0.525 & $10.97+0.53$ (slope) & 0.194 & $<0.001$ \\
\hline & \multicolumn{5}{|c|}{ Exponential } \\
\hline & $\mathrm{n}$ & $\beta$ & $\operatorname{ROS}=a e^{b x}$ & Adj. $\mathrm{R}^{2}$ & $p$ \\
\hline Det. & 157 & 0.031 & $6.65 e^{(0.031) \text { slope }}$ & 0.075 & $<0.001$ \\
\hline Th 1. & 291 & 0.044 & $7.40 e^{(0.044) \text { slope }}$ & 0.513 & $<0.001$ \\
\hline Th 2. & 372 & 0.046 & $6.77 e^{(0.046) \text { slope }}$ & 0.548 & $<0.001$ \\
\hline Th 3. & 123 & 0.043 & $5.63 e^{(0.043) \text { slope }}$ & 0.536 & $<0.001$ \\
\hline \multirow[t]{3}{*}{ Th 4.} & 332 & 0.028 & $7.75 e^{(0.043) \text { slope }}$ & 0.191 & $<0.001$ \\
\hline & \multicolumn{5}{|c|}{ Power } \\
\hline & $\mathrm{n}$ & $\beta$ & $\mathrm{ROS}=a x^{b}$ & Adj. $R^{2}$ & $p$ \\
\hline Det. & 157 & 1.936 & 2.20 (slope) $)^{1.936}$ & 0.078 & $<0.001$ \\
\hline Th 1. & 291 & 4.979 & 1.13 (slope) ${ }^{4.979}$ & 0.490 & $<0.001$ \\
\hline Th 2 . & 372 & 4.960 & 1.00 (slope) ${ }^{4.960}$ & 0.533 & $<0.001$ \\
\hline Th 3. & 123 & 3.807 & 1.10 (slope) ${ }^{3.807}$ & 0.513 & $<0.001$ \\
\hline Th 4 . & 332 & 3.028 & 2.31 (slope) ${ }^{3.028}$ & 0.173 & $<0.001$ \\
\hline
\end{tabular}



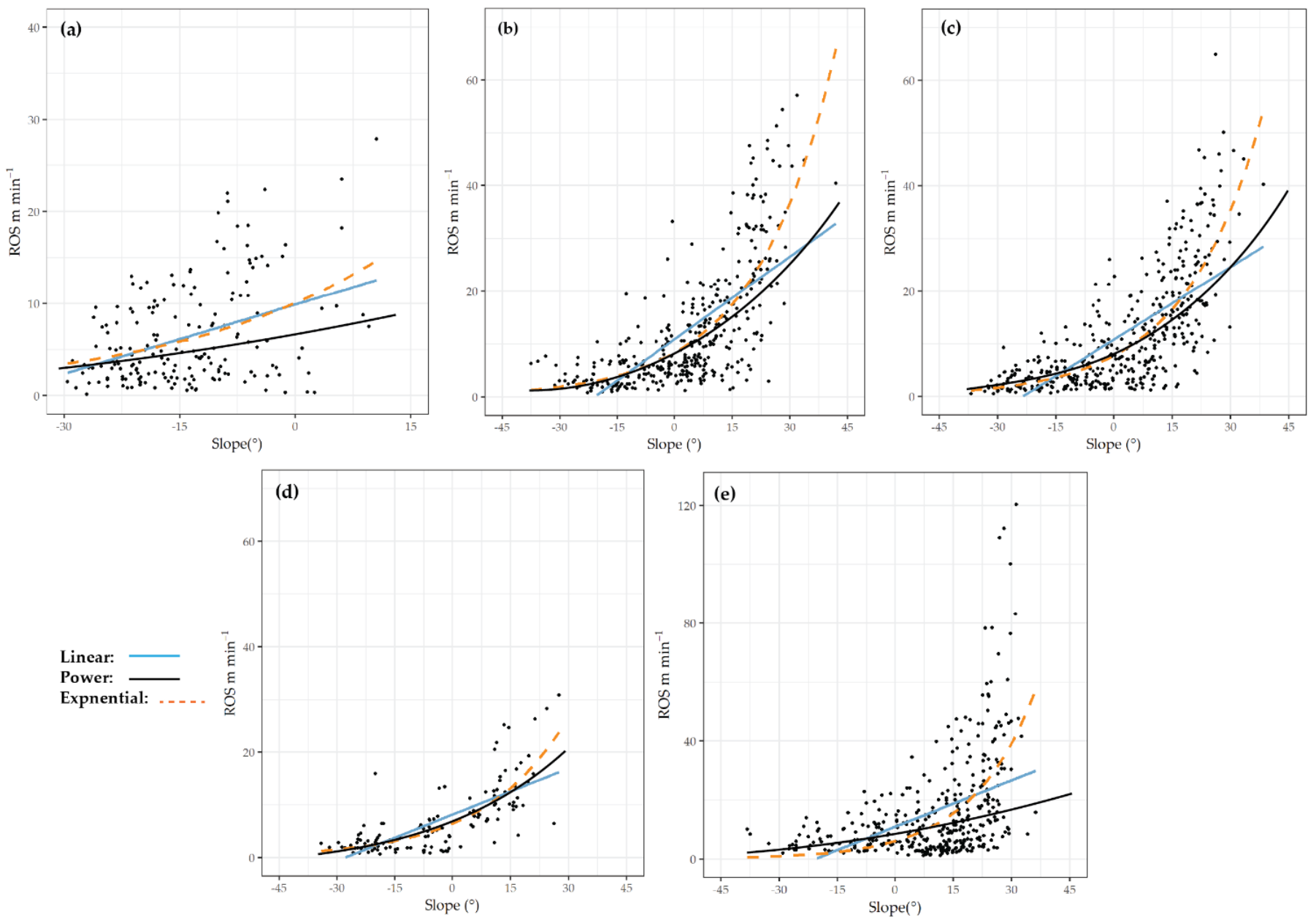

Figure 6. Scatter plots of linear, exponential, and power regression fits between rate of spread estimates and directional slope LSU means. (a) Detwiler sequence. (b) Thomas 1. (c) Thomas 2. (d) Thomas 3. (e) Thomas 4.

\subsection{Multivariate Analyses}

Multiple forward/backward stepwise linear regression models were run with all covariates as initial inputs for each sequence to gain insights on variable interactions and combined influences on ROS (Table 5). Directional slope remained the most significant predictor of ROS (average std. $\beta$ coef. of 0.381). Except for the Detwiler sequence, NDVI-U was included as a significant covariate with ROS. Similarly, GRVI-U was a marginally significant predictor of ROS for two of five sequences. The Thomas 3 model explained the greatest variance in ROS estimates (54\%) and included directional slope, shrub, and NDVI-U as significant covariates. Levels of statistical significance for GFFC varied largely by sequence. Rock/bare soil were included in multiple regression models for Detwiler and Thomas 2 and Thomas 4 . Herb fraction for Detwiler and Thomas 1 models exhibited interaction with other covariates and ROS, and thus were included in multivariate models. Absolute std. $\beta$ coefficient averages for fuel covariates were 0.12 and 0.14 for SVIs and GFFC, respectively. Overall, when compared to directional slope, all image-derived fuel covariates contributed only a small fraction to ROS variance explanation (12-17\%).

Table 5. Multivariate regression results. Cross-validated (CV) $R^{2}$ are 10-fold. Variance inflation factor (VIF) is maximum reported for model.

\begin{tabular}{|c|c|c|c|c|c|c|c|c|c|c|c|}
\hline & \multicolumn{5}{|c|}{ Multiple Regression } & \multicolumn{6}{|c|}{ Forward/Backward Stepwise Regression } \\
\hline & AIC & VIF & Adj. $R^{2}$ & $\mathrm{CV} \mathrm{R}^{2}$ & $p$ & AIC & VIF & Significant Variables & Adj. $R^{2}$ & $\mathrm{CV} \mathrm{R}^{2}$ & $p$ \\
\hline Det. & 1126.83 & 19 & 0.235 & 0.243 & $<0.001$ & 1121.31 & 1 & Slope, herb, tree, rock/bare soil & 0.237 & 0.273 & $<0.001$ \\
\hline Th 1. & 2546.52 & 11 & 0.503 & 0.519 & 0.001 & 2542.85 & 3 & Slope, herb, tree, NDVI-U, GRVI-U & 0.505 & 0.524 & $<0.001$ \\
\hline Th 2. & 2899.42 & 7 & 0.488 & 0.494 & 0.004 & 2895.55 & 4 & Slope, rock/bare soil, NDVI-U, GRVI-U & 0.490 & 0.499 & 0.004 \\
\hline Th 3. & 755.32 & 36 & 0.529 & 0.584 & 0.001 & 747.61 & 1 & Slope, shrub, NDVI-U & 0.543 & 0.574 & $<0.001$ \\
\hline Th 4. & 3136.14 & 11 & 0.249 & 0.259 & $<0.001$ & 3133.22 & 4 & Slope, tree, rock/bare soil, NDVI-U & 0.251 & 0.261 & $<0.001$ \\
\hline
\end{tabular}




\section{Discussion}

Weather, fuel, and topographic conditions and properties are the factors that control wildfire spread [29-33]. Most empirical studies investigating environmental controls on fire spread are limited to laboratory and outdoor fire experiments, or studies based on coarse-scale satellite images of natural events e.g., $[4,8,9,66]$. The primary objectives of this research were to evaluate landscape-scale terrain and fuel controls on fire spread rates derived from repetitive-ATIR imagery collected during portions of two extreme wildfire events. This study directly builds on Stow et al. $[63,64]$ by linking detailed ATIR wildfire spread measurements to geospatial data representing fuel and topographic distributions derived from prefire NAIP orthoimagery and USGS DEMs.

\subsection{Fuel Covariate Findings}

Fuel properties which influence fire behavior are difficult to measure and map due to their high variability in time and space [37-39]. For this reason, image-derived spectral vegetation indices and growth form maps were tested as spatially explicit proxies of fuel load distributions. The low and mostly nonsignificant correlations between ROS and imaged-derived fuel covariates suggest that (1) neither the SVIs or GFFC were stable predictors of ROS for the particular wildfire events and landscapes studied here, (2) fuel load was not a significant control on spread rates at the study sites examined in this research, or conversely, (3) the temporal resolution of NAIP imagery produced inaccurate estimates of the spatial characteristics of vegetation at the study areas imaged within the extreme wildfire events. Similarly, wind speed, which cannot be incorporated at the space-time scales of our landscape statistical analysis, may dominate the unexplained variance and weaken any influence of fuel covariates on ROS (see discussion on weather below). However, when comparing model coefficients between separate study areas, GFFC depicts more consistent relationships with ROS estimates than SVIs. For example, a negative relationship was commonly found for study areas containing LSUs with larger tree or rock/bare soil fractions (std. $\beta$ average of -0.613 ). Conversely, relationships between SVIs and ROS varied largely by study area, and no clear relationship was discernable from model coefficients. Some past studies examining the applicability of SVIs as surrogates of fuel load or biomass using moderate to coarse-satellite images report promising results e.g., $[36,39,40]$, indicating that SVIs are more closely associated with ROS at landscape-scales when coupled with terrain variables [42-44] and derived from orthoimagery captured just prior to the burn event $[36,58]$.

The inclusion of growth forms and SVIs in multivariate models did increase the predictability and variance explanation of ROS. Cross-validated $R^{2}$ values routinely increased over standard adj. $R^{2}$ metrics in multivariate models. Similarly, the stratification of directional slope by fuel class (derived from GFFC estimates) increased variance explanation of ROS for Detwiler and Thomas 4. This supports what is generally known about fire behavior, that variations in fire spread rates are likely the result of complex landscape-scale interactions between fuel, terrain, and weather characteristics $[29,37,89]$. The statistical significance of bivariate and multivariate regression models for fuel covariates at Detwiler and Thomas 4 show separate controls on ROS at specific times of burning within the extreme wildfire events. Detwiler and Thomas 4 both exhibited significantly higher FireBuster and RAWS wind speeds compared to other sequences (Table 4). The ancillary wind information coupled with fuel covariate findings at Thomas 4 indicate that fire spread controls during extreme wildfire events occur at landscape scales [53]. Further, homogeneity of vegetation cover type has been linked to greater fire size and ROS by Viedma et al. [90] and Holsinger et al. [91]. To further investigate this point, we analyzed samples in the top 95th percentile of ROS estimates and found most of the associated LSUs had shrub or herbaceous cover fractions between $90 \%$ and $100 \%$. LSUs linked to lower ROS percentile groups (e.g., bottom 20th percentile) contained larger variation of GF type. These findings correspond with many former studies, in that fuel heterogeneity or fragmentation can restrain fire propagation and $\operatorname{ROS}[90,91]$ and should be investigated further. 


\subsection{Topographic Covariate Findings}

Slope directly regulates fire spread through energy transfer of flaming biomass along fire fronts and its relationship with ROS has been postulated as a curvilinear function [4,49-51]. Many findings indicate slope steepness has a dramatic effect on fire spread [49,50], however, the effects of slope on ROS in chaparral fuels are largely limited to laboratory settings due to the difficulty of isolating its influence from other variables (wind and fuels) during outdoor experiments and extreme wildfire events [14]. To evaluate nonstatic terrain controls on wildfire spread rates derived from the high-temporal resolution ATIR imagery, we designed a customized directional slope covariate to calculate signed-slope angles in the relative direction of fire propagation. We also attempted to isolate directional slope by orientation and fuel classes derived from GFFC estimates (Table 2 c).

Directional slope is the most explanatory covariate for all study sequences, accounting for more than $50 \%$ (adj. $R^{2} \geq 0.500$ ) of the variance in ROS estimates for three of five of the image sequences (Table 4). All regression models were statistically significant for directional slope on ROS for all sequences. Slightly higher model fits for exponential and power regressions with directional slope suggest the relationship with ROS is best described as a positive nonlinear function. An important finding from our topographic analyses on ROS is that exponential regression results were consistent between study areas. For example, constants in functions derived from exponential regression (or $a$ in $a e^{b x}$ ) suggest the $y$-intercepts of the separate models varied little among study areas $\left(5.6-7.4 \mathrm{~m} \mathrm{~min}^{-1}\right)$. Growth rates of ROS (per unit increase in directional slope) were also consistent between separate study areas. For instance, growth factors (or $b$ in $a e^{b x}$ ) in exponential functions only varied from $3.0 \%$ for Detwiler to $4.8 \%$ for Thomas $2(\Delta 1.8 \%)$.

We further examined directional slope data for LSUs associated with the top 95th percentile of ROS estimates and discovered maximum rates of spread coincide with slope angles between 20 and $40^{\circ}$; none of these samples associated with rapid fire spread had negative slopes. These findings contradict those from Vega et al. [92] and Catchpole et al. [93], who have proposed that slope controls on ROS in shrubland fires is less than forests [14,52].

While the influence of directional slope on ROS is clear and consistent within the contexts of the study fires and space and time scales of analysis, its importance as a controlling variable may vary as a function of space and time scales [14,52]. We characterized the average ROS and slope trends for the four Thomas Fire sequences which were all generally upslope fire progressions (unlike the Detwiler Fire sequence), as shown in Table 6. The ROS per degree of upslope trends at characteristic length scales of several $\mathrm{km}$ (rather than tens to a few hundred meters for the LSU analyses) are also listed in Table 6. These trend characteristics show that the relationship between ROS and slope are consistent between Thomas 1, 2, and 3 (imaged on the same day). The larger ratio between ROS and slope at Thomas 4 indicates that wind was likely the predominant control on fire spread. This is confirmed by the higher wind speeds recorded at Thomas 4 and the sequence's stronger relationships between fuel covariates and ROS. In this context, the influence of wind on ROS could also apply to the Detwiler sequence, which also exhibited a higher statistical significance with fuel covariates, lower significance with directional slope, and higher average wind speed. An equally important inference is that the directional slope covariate used in this research may be capturing topographic influences on surface winds $[54,58]$. 
Table 6. Slope trend for Thomas fire sequences. Metrics in table summarize the full range of a sequences (time $=1$ front to time $=$ end front).

\begin{tabular}{ccccccc}
\hline Sequence & $\begin{array}{c}\text { Time Elapsed } \\
\text { (HH:MM:SS) }\end{array}$ & $\begin{array}{c}\text { Total Distance } \\
(\mathbf{m})\end{array}$ & $\begin{array}{c}\text { ROS } \\
\left(\mathbf{m} \mathbf{m i n}^{-\mathbf{1}}\right)\end{array}$ & $\begin{array}{c}\text { Elevation Gain } \\
(\mathbf{m})\end{array}$ & $\begin{array}{c}\text { Slope Trend } \\
(\mathbf{d e g})\end{array}$ & $\begin{array}{c}\text { ROS/Slope } \\
\left(\mathbf{m} \mathbf{m i n}^{-\mathbf{1} / \mathbf{d e g}} \mathbf{- 1}\right)\end{array}$ \\
\hline Thomas 1 & $3: 12: 59$ & 1884.52 & 9.76 & 670.78 & 19.54 & \\
Thomas 2 & $3: 23: 17$ & 2387.74 & 11.74 & 444.72 & 10.53 & 0.5 \\
Thomas 3 & $0: 42: 30$ & 504.00 & 11.86 & 124.01 & 13.50 & 0.11 \\
Thomas 4 & $0: 49: 04$ & 2379.24 & 48.48 & 465.16 & 11.06 & 4.38 \\
\hline
\end{tabular}

Excluding the Detwiler and Thomas 4 sequences, stratifying directional slope by orientation and fuel class showed similar findings as unstratified models. However, our qualitative observations of fire spread along ridgetops and valley bottoms (Figure 7) indicate that the stratification scheme used in this research did not isolate relationships effectively; or high homogeneity of vegetation type and cover largely negated the stratification approach. Moritz et al. [89] postulated that topographic "fences" and "corridors" may impede or facilitate wildfire spread and occurrence during extreme wildfire events. Our qualitative observations of topography influencing fire spread from geovisualizations of active fire fronts derived from ATIR time sequences (Figure 7) support this assumption and are also consistent with past studies describing how convective or radiative mechanisms of wildfire spread are (1) strongly influenced along ridgetops and valley bottoms, and/or (2) these features have a large effect on surface winds and fuel conditions $[48,58,89,94]$. Moreover, the restriction of fire spread along these topographic features do support past findings that fire "fences" occur on landscape scales [89-91].

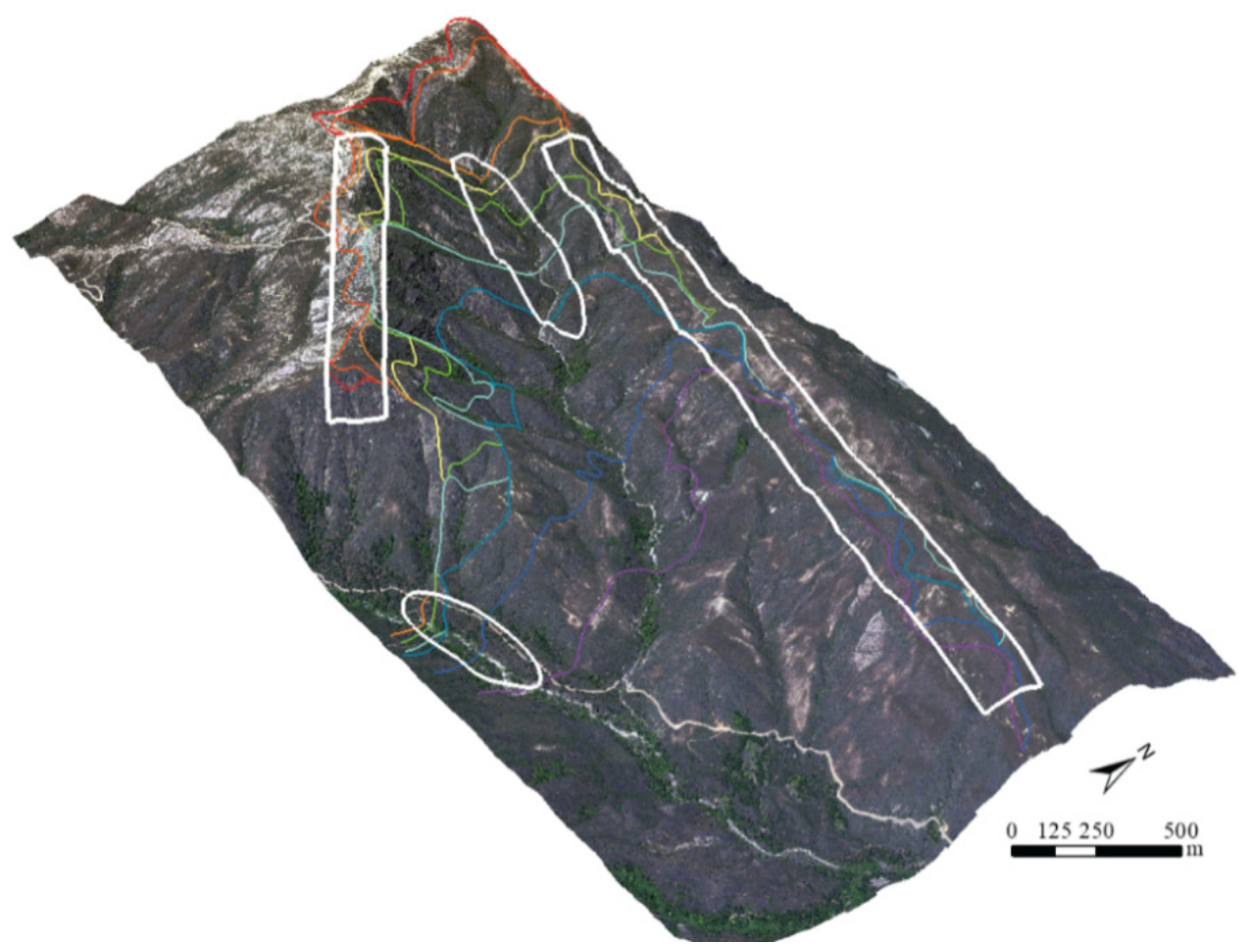

Figure 7. Zones of impeded fire spread at Thomas sequence 4. White rectangle polygons showing fire spread along ridgetops and elliptical polygons highlighting spread along valley bottoms. Progression of color spectrum illustrates movement of fire fronts over time. 


\subsection{Weather-Related Findings}

Most of the evidence associated with weather effects on fire spread for this study is limited to general ROS trends relative to wind direction, velocity, and relative humidity from RAWS observations and FireBuster forecasts that correspond most closely to the space-time domains of our image-based fire spread estimates. RAWS data and FireBuster predictions associated with ATIR collection periods and locations are reported in Table 4. The spatial, and especially temporal scales of both data types are too coarse to be analyzed statistically in a direct manner with ROS. However, the FireBuster predictions and RAWS data do help shed light on regression analyses.

Besides reported winds for Thomas 4 and Detwiler, RAWS and FireBuster reports for other sequences show low wind speed. The incorporation of topographic and meteorological data in the spatially explicit FireBuster model [74] are also likely to produce estimates of weather variables that are more indicative of the site-specific fire spread conditions where ATIR image sequences were captured, though at coarser spatial and temporal scales. For example, wind direction reported from nearest RAWS to Detwiler (13.3 km North) are directionally opposite to fire spread directions documented by spread-vector bearings. Contrastingly, FireBuster predictions for the time and location of the Detwiler sequence characterize wind directions consistent with fire spread direction.

The most meaningful finding related to general weather versus ROS relationships is that wind speeds and ROS were substantially higher, and relative humidity lower during the Thomas 4 and Detwiler sequences than for the Thomas 1-3, as shown in Table 4 . The data and estimates reveal that Santa Ana weather conditions prevailed during the Thomas 4 sequence on 09 December 2020, but not necessarily on the previous data when the other Thomas sequences were imaged. Although the burn area associated with the Thomas 4 sequence, just $15 \mathrm{~km}$ west of Thomas 1-3, the relationships between directional slope and ROS are substantially different between the sequences that exhibit relatively higher wind speeds (Detwiler and Thomas 4). Further, the mean and median ROS estimates for Thomas 4 are considerably higher than other sequences. Higher ROS for Thomas 4 is likely associated with the faster wind speeds reported by nearest RAWS data and FireBuster estimates. This suggests that fire behavior for Thomas 4 and Detwiler were more winddriven and the higher wind speeds may have substantially reduced the relative influence of slope on ROS [14].

The Thomas Fire covered a vast, topographically diverse area and occurred during a two-week period intermittent Santa Ana weather condition. Thus, while some fire growth areas and periods were wind-driven, such as the initial run on December 4-5, others were topographically sheltered from the Santa Ana winds and instead, driven by 'fire-induced winds' [95], or intermittently exposed to the strong ambient winds [96].

\section{Conclusions}

Through this study we demonstrated that repetitive ATIR imagery from the FireMapper ${ }^{\mathrm{TM}} 2.0$ imaging system facilitates attainment of broader knowledge of the relationships between extreme wildfire behavior and controlling environmental factors. Additionally, such landscape-level estimates of ROS provide could provide an excellent source of reference data for validating fire spread theory and simulation models [18-20]. Continuing ATIR data collection during extreme wildfire events in disparate ecosystem, terrain, and climate types is of the utmost importance, and would encourage the establishment of a comprehensive data set for future fire spread research and validation purposes.

We also document procedures for relatively short-interval, time-sequential ATIR imagery collection with the FireMapper 2.0 system for quantifying ROS during extreme fire events and evaluating environmental controls on fire spread at landscape scales. We identified covariate relationships, interactions, and influences with ROS estimates that help validate and expand upon similar work conducted for larger and smaller scales. We provide evidence from the 2017 Thomas and Detwiler fires that directional slope can be a strong control variable on ROS in shrubland landscapes, and its influence can be effectively 
expressed as a curvilinear function. We postulate that calculating directional slope in advance of an active fire front, coupled with dominant wind data, could provide fire managers and modelers better ability to predict wildfire spread and focus fuel treatment projects, similar to findings from Viedma et al. [54] and Coen et al. [58].

This study is the first attempt at isolating and statistically analyzing landscape-scale covariate relationships with high spatial and temporal resolution fire spread measurements collected during extreme wildfire events. The Detwiler and Thomas fire events burned over 140,000 ha of land, and spread through diverse variations of terrain, fuel, and weather. Observations and results drawn from this study are necessarily limited to the specific fire spread behaviors and landscape characteristics associated with the study fires captured during ATIR imaging. Moreover, the influence of weather on ROS estimates is challenging to account for in the statistical analyses due primarily to the nature of capturing wind speed and direction data for individual LSUs and at the temporal resolution of ATIR imaging during such events. However, the effects of Santa Ana wind and humidity conditions can be discerned from the differences in ROS and model fits with directional slope when comparing results for Thomas sequence 4 relative to sequences 1 through 3 [96].

Follow-on research pertaining to spatial-scale and nonlinear relationships between ROS estimates and landscape covariates should be conducted. This could include buffering spread vectors to generate larger landscape sample units that may account for uncertainty in actual fire spread directions [64]. Spatial association effects on statistical analyses could be evaluated using Geographically Weighted Regression (GWR) and/or Eigenvector-based Spatial Filtering (ESF) regression techniques. Nonlinear, nonparametric machine learning approaches such as regression trees (RT) and random forest (RF) regression should also be explored. Similarly, this research focused on analyzing long runs of fire spread that were easily tractable from ATIR image sequences. However, focus should be given to the spatial relationships and impact of spotting behaviors on ROS that were omitted in this research to focus on the full fire runs captured by ATIR sequences.

Future research on imaged-derived fuel covariate relationships with ROS would benefit from studies of wildfires in different ecosystems with different and particularly more heterogenous fuel compositions. This would also help determine if the weak relationship between ROS estimates and fuel covariates were limited by homogenous fuel conditions within the study fire sequence zones. The inclusion of prefire Light Detection and Ranging (LiDAR) data for the characterization and mapping of fuels would also likely enhance assessment of fuel controls.

The predictive capability of directional slope and its statistical relationship with ROS and interaction with wind speed should be explored further. Moreover, wind direction and velocity data at spatial and temporal scales closer to those of the ATIR image sequences would allow better understanding of weather influences on ROS. Evaluating the influence of terrain features that impede or enhance wildfire spread could also be examined by exploring ROS relationships with topographic index metrics [97].

Author Contributions: Conceptualization, G.M.S., D.A.S., P.J.R., R.G.T. and J.L.C.; Methodology, G.M.S., D.A.S., P.J.R., R.G.T. and J.L.C.; Formal Analysis, G.M.S. and D.A.S.; Resources, P.J.R., R.G.T., D.A.S. and J.L.C.; Writing-original draft preparation, G.M.S., D.A.S. and J.L.C.; Writing-review and editing, G.M.S., D.A.S., P.J.R., R.G.T. and J.L.C.; Funding acquisition, D.A.S., P.J.R., J.L.C. and R.G.T. All authors have read and agreed to the published version of the manuscript.

Funding: This research was funded by the National Science Foundation (NSF), Division of Social, Behavioral and Economic Research, Geography and Spatial Sciences program grant G00011220. NCAR is sponsored by NSF. Any opinions, findings, and conclusions or recommendations expressed in this material are the authors' and do not reflect the views of NSF.

Data Availability Statement: The data that support the findings of this study are available upon request.

Conflicts of Interest: The authors declare no conflict of interest. 


\section{References}

1. Certini, G. Effects of Fire on Properties of Forest Soils: A Review. Oecologia 2005, 143, 1-10. [CrossRef] [PubMed]

2. Bowman, D.M.; Balch, J.K.; Artaxo, P.; Bond, W.J.; Carlson, J.M.; Cochrane, M.A.; D'Antonia, C.M.; Defires, R.S.; Doyle, J.C.; Harrison, S.P.; et al. Fire in the Earth System. Science 2009, 324, 481-484. [CrossRef] [PubMed]

3. Cal Fire Incident Archive. Available online: http:/ / www.fire.ca.gov/incidents/2017 (accessed on 18 January 2020).

4. Rothermel, R.C. A Mathematical Model for Predicting Fire Spread in Wildland Fuels; Intermountain Forest and Range Experiment Station Research Paper INT-115; USDA Forest Service: Ogden, UT, USA, 1972.

5. Viegas, D.X. Slope and wind effects on fire propagation. Int. J. Wildland Fire 2004, 13, 143-156. [CrossRef]

6. Sanchez-Monroy, X.; Mell, W.; Torres-Arenas, J.; Butler, B.W. Fire spread upslope: Numerical simulation of laboratory experiments. Fire Saf. J. 2019, 108, 102844. [CrossRef]

7. Dupuy, J.L.; Marachal, J.; Portier, D.; Valette, J.C. The effects of slope and fuel bed width on laboratory fire behavior. Int. J. Wildland Fire 2011, 20, 272-288. [CrossRef]

8. Morandini, F.; Silvani, X. Experimental investigation of the physical mechanisms governing the spread of wildfires. Int. J. Wildland Fire 2010, 19, 570-582. [CrossRef]

9. Stephens, S.L.; Weise, D.R.; Fry, D.L.; Keiffer, R.J.; Dawson, J.; Koo, E.; Potts, J.; Pagni, P.J. Measuring the rate of spread of chaparral prescribed fires in northern California. Fire Ecol. 2008, 4, 74-86. [CrossRef]

10. Clements, C.B.; Lareau, N.P.; Seto, D.; Contezac, J.; Davis, B.; Teske, C.; Zajkowski, T.J.; Hudak, A.T.; Bright, B.C.; Dickinson, M.B.; et al. Fire weather conditions and fire-atmosphere interactions observed during low-intensity prescribed fires-RxCADRE 2012. Int. J. Wildland Fire 2016, 25, 90-101. [CrossRef]

11. Finney, M.A. FARSITE, Fire Area Simulator—Model Development and Evaluation; USDA Forest Service, Rocky Mountain Research Station: Fort Collins, CO, USA, 1998.

12. Cheney, N.P.; Gould, J.S.; Catchpole, W.R. Prediction of fire spread in grasslands. Int. J. Wildland Fire 1998, 8, 1-13. [CrossRef]

13. Cruz, M.G.; Alexander, M.E.; Wakimoto, R.H. Development and testing of models for predicting crown fire rate of spread in conifer forest stands. Can. J. For. Res. 2005, 35, 1626-1639. [CrossRef]

14. Anderson, W.R.; Cruz, M.G.; Fernandes, P.M.; McCaw, L.; Vega, J.A.; Bradstock, R.A.; Fogarty, L.; Gould, J.; McCarthy, G.; Marsden-Smedley, J.B.; et al. A generic, empirical-based model for predicting rate of fire spread in shrublands. Int. J. Wild. Fire 2015, 24, 443-460. [CrossRef]

15. Achtemeier, G.L. Field validation of a free-agent cellular automata model of fire spread with fire-atmosphere coupling. Int. J. Wildland Fire 2013, 22, 148-156. [CrossRef]

16. Alexander, M.E.; Cruz, M.G. Evaluating a model for predicting active crown fire rate of spread using wildfire observations. Can. J. For. Res. 2006, 36, 3015-3028. [CrossRef]

17. Hoffman, C.M.; Canfield, J.; Lin, R.R.; Mell, W.; Sieg, C.H.; Pimont, F.; Ziegler, J. Evaluating crown fire rate of spread predictions from physics-based models. Fire Tech. 2016, 52, 221-237. [CrossRef]

18. Riley, K.; Thompson, M. An uncertainty analysis of wildfire modeling. Nat. Haz. Uncert. Assess. Mod. Dec. Sup. 2017, 223, 193-213.

19. Cardil, A.; Mondedero, S.; Ramirez, J.; Silva, C.A. Assessing and reinitializing wildland fire simulations through satellite active fire data. J. Environ. Manag. 2019, 231, 996-1003. [CrossRef]

20. Finney, M.A.; McHugh, C.W.; Grenfell, C.J. Stand- and landscape-level effects of prescribed burning on two Arizona Wildfires. Can. J. For. Res. 2005, 35, 1714-1722. [CrossRef]

21. Cruz, M.G.; Alexander, M.E.; Sullivan, A.L. Mantras of wildland fire behaviour modelling: Facts or fallacies? Int. J. Wildland Fire 2017, 26, 973-981. [CrossRef]

22. Riggan, P.J.; Tissell, R.G. Airborne remote sensing of wildland fires. Dev. Environ. Sci. 2008, 8, 139-168.

23. Lentile, L.B.; Holden, Z.A.; Smith, A.M.; Falkowski, M.J.; Hudak, A.T.; Morgan, P.; Lewis, S.A.; Gessler, P.E.; Benson, N.C. Remote sensing techniques to assess active fire characteristics and post-fire effects. Int. J. Wildland Fire 2006, 15, 319-345. [CrossRef]

24. Tedim, F.; Leone, V.; Amraoui, M.; Bouillon, C.; Coughlan, M.R.; Delogu, G.M.; Fernandes, P.M.; Ferreira, C.; McCaffrey, S.; McGee, T.K.; et al. Defining extreme wildfire events: Difficulties, challenges, and impacts. Fire 2018, 1, 9. [CrossRef]

25. Loudermilk, E.L.; O’Brien, J.J.; Mitchell, R.J.; Cropper, W.P.; Hiers, J.K.; Grunwald, S.; Grego, J.; Fernandez-Diaz, J.C. Linking complex forest fuel structure and fire behaviour at fine scales. Int. J. Wildland Fire 2012, 21, 882-893. [CrossRef]

26. Ferreira, L.; Constantino, M.F.; Borges, J.G.; Garcia-Gonzalo, J. Addressing wildfire risk in a landscape-level scheduling model: An application in Portugal. Forest Sci. 2015, 61, 266-277. [CrossRef]

27. Moreira, F.; Viedma, O.; Arianoutsou, M.; Curt, T.; Koutsias, N.; Rigolot, E.; Barbati, A.; Corona, P.; Vaz, P.; Xanthopoulos, G.; et al. Landscape-wildfire interactions in southern Europe: Implications for landscape management. J. Environ. Manag. 2011, 92, 2389-2402. [CrossRef] [PubMed]

28. Finney, M.A.; Seli, R.C.; McHugh, C.W.; Ager, A.A.; Bahro, B.; Agee, J.K. Simulation of long-term landscape-level fuel treatment effects on large wildfires. Int. J. Wildland Fire 2008, 16, 712-727. [CrossRef]

29. Countryman, C.M. The concept of fire environment. Fire Manag. Today 2004, 64, 49-52.

30. Albini, F.A. Estimating Wildfire Behavior and Effects; Intermountain Forest and Range Experiment Station General Technical Report; Department of Agriculture, Forest Service: Ogden, UT, USA, 1976. 
31. Heyerdahl, E.K.; Brubaker, L.B.; Agee, J.K. Spatial controls of historical fire regimes: A multiscale example from the interior west, USA. Ecology 2001, 82, 660-678. [CrossRef]

32. Coen, J.L. Some new basics of fire behavior. Fire Manag. Today 2011, 71, 37.

33. McKenzie, D.; Miller, C.; Falk, D.A. The Landscape Ecology of Fire; Springer: Dordrecht, The Netherlands, 2011.

34. Anderson, H.E. Aids to Determining Fuel Models for Estimating Fire Behavior; Intermountain Forest and Range Experiment Station Research Paper; USDA Forest Service: Ogden, UT, USA, 1981.

35. Keane, R.E.; Burgan, R.; Van Wagtendonk, J. Mapping wildland fuels for fire management across multiple scales: Integrating remote sensing, GIS, and biophysical modeling. Int. J. Wildland Fire 2001, 10, 301-319. [CrossRef]

36. Beyers, J.L.; Riggan, P.J.; Weise, D.; Paysen, T.; Narog, M. Age-Class Mosaics and Wind-Driven Fire: Further Fuel for the Debate. 2012. Available online: https:/ / digitalcommons.unl.edu (accessed on 18 February 2020).

37. Riggan, P.J.; Franklin, S.E.; Brass, J.A.; Brooks, F.E. Perspectives on fire management in mediterranean ecosystems of southern California. In The Role of Fire in Mediterranean-Type Ecosystems; Springer: New York, NY, USA, 1994; pp. $140-162$.

38. Arroyo, L.A.; Healey, S.P.; Cohen, W.B.; Cocero, D.; Manzanera, J.A. Using object-oriented classification and high-resolution imagery to map fuel types in a Mediterranean region. J. Geophys. Res. Biogeosci. 2006, 111, G04S04. [CrossRef]

39. Uyeda, K.A.; Stow, D.A.; Riggan, P.J. Tracking MODIS NDVI time series to estimate fuel accumulation. Remote Sens. Lett. 2015, 6, 587-596. [CrossRef]

40. Uyeda, K.A.; Stow, D.A.; Roberts, D.A.; Riggan, P.J. Combining ground-based measurements and MODIS-based spectral vegetation indices to track biomass accumulation in post-fire chaparral. Int. J. Remote. Sens. 2017, 38, 728-741. [CrossRef]

41. Mueller-Dombois, D.; Ellenberg, H. Aims and Methods of Vegetation Ecology; Wiley: Hoboken, NJ, USA, 1974.

42. Riaño, D.; Chuvieco, E.; Ustin, S.L.; Salas, J.; Rodríguez-Pérez, J.R.; Ribeiro, L.M.; Viegas, D.X.; Moreno, J.M.; Fernández, H. Estimation of shrub height for fuel-type mapping combining airborne LiDAR and simultaneous color infrared ortho imaging. Int. J. Wildland Fire 2007, 16, 341-348. [CrossRef]

43. Galidaki, G.; Zianis, D.; Gitas, I.; Radoglou, K.; Karathanassi, V.; Tsakiri-Strati, M.; Woodhouse, I.; Mallinis, G. Vegetation biomass estimation with remote sensing: Focus on forest and other wooded land over the Mediterranean ecosystem. Int. J. Remote. Sens. 2017, 38, 1940-1966. [CrossRef]

44. Chuvieco, E.; Cocero, D.; Riano, D.; Martin, P.; Martınez-Vega, J.; de la Riva, J.; Pérez, F. Combining NDVI and surface temperature for the estimation of live fuel moisture content in forest fire danger rating. Remote Sens. Environ. 2004, 92, 322-331. [CrossRef]

45. Garrigues, S.; Lacaze, R.; Baret, F.J.; Morisette, T.M.; Weiss, J.T.; Nickeson, M.; Fernandes, R.; Plummer, S.; Shabanov, N.V.; Myneni, R.B.; et al. Validation and intercomparison of global Leaf Area Index products derived from remote sensing data. J. Geophys. Res. Biogeosci. 2008, 113, G02028. [CrossRef]

46. Butler, B.W.; Anderson, W.R.; Catchpole, E.A. Influence of Slope on Fire Spread Rate; RMRS-P-46CD; USDA Forest Service, Rocky Mountain Research Station: Ogden, UT, USA, 2007; pp. 75-82.

47. Potts, D.F.; Ryan, K.C.; Zurring, H.R. Stratified sampling for determining duff moisture in mountainous terrain. West. J. Appl. For. 1986, 11, 29-30. [CrossRef]

48. Raaflaub, L.D.; Valeo, C.; Johnson, E.A. Slope effects on the spatial variations in duff moisture. Ecohydology 2012, 5, 819-825. [CrossRef]

49. Van Wagner, C.E. Effect of slope on fire spread rate. Can. For. Serv. Monthly Res. Notes 1977, 33, 7-8.

50. McArthur, A.G. Fire behaviour in eucalyptus forests. In Forestry and Timber Bureau Leaflet; Commonwealth Department of National Development; Australian Government Publishing Service: Hawthorn, Australia, 1967; Volume 107.

51. Noble, I.R.; Gill, A.M.; Bary, G.A.V. McArthur's fire-danger meters expressed as equations. Aust. J. Ecol. 1980, 5, $201-203$. [CrossRef]

52. Sullivan, A.L.; Sharples, J.J.; Matthews, S.; Plucinski, M.P.A. Downslope fire spread correction factor based on landscape-scale fire behaviour. Environ. Mod. Soft. 2014, 62, 153-163. [CrossRef]

53. Blodgett, N.; Stow, D.A.; Franklin, J.; Hope, A.S. Effect of fire weather, fuel age and topography on patterns of remnant vegetation following a large fire event in southern California, USA. Int. J. Wildland Fire 2010, 19, 415-426. [CrossRef]

54. Viedma, O.; Quesada, J.; Torres, I.; De Santis, A.; Moreno, J.M. Fire severity in a large fire in a Pinus pinaster forest is highly predictable from burning conditions, stand structure, and topography. Ecosystems 2015, 18, 237-250. [CrossRef]

55. Dong, X.U.; Li-min, D.; Guo-fan, S.; Lei, T.; Hui, W. Forest fire risk zone mapping from satellite images and GIS for Baihe Forestry Bureau, Jilin, China. J. For. Res. 2005, 16, 169-174. [CrossRef]

56. Finney, M.A.; Cohen, J.D.; Forthofer, J.M.; McAllister, S.S.; Gollner, M.J.; Gorham, D.J.; Saito, K.; Akafuah, N.K.; Adam, B.A.; English, J.D. Role of buoyant flame dynamics in wildfire spread. Proc. Natl. Acad. Sci. USA 2015, 112, 9833-9838. [CrossRef] [PubMed]

57. Mermoz, M.; Kitzberger, T.; Veblen, T.T. Landscape influences on occurrence and spread of wildfires in Patagonian forests and shrublands. Ecology 2005, 86, 2705-2715. [CrossRef]

58. Coen, J.L.; Stavros, E.N.; Fites-Kaufman, J.A. Deconstructing the King megafire. Ecol. Appl. 2018, 28, 1565-1580. [CrossRef]

59. Coen, J.L.; Schroeder, W. The high park fire: Coupled weather-wildland fire model simulation of a windstorm-driven wildfire in Colorado's Front Range. J. Geophys. Res. Atmos. 2015, 120, 131-146. [CrossRef]

60. Wang, X.; Parisien, M.; Flannigan, M.D.; Parks, S.A.; Anderson, K.R.; Little, J.M.; Taylor, S.W. The potential and realized spread of wildfires across Canada. Glob. Chang. Biol. 2014, 20, 2518-2530. [CrossRef] 
61. Schoennagel, T.; Veblen, T.; Romme, W. Interaction of fire, fuels, and climate across Rocky Mountain Forests. BioScience 2004, 54, 661-667. [CrossRef]

62. Ollero, A.; Merino, L. Unmanned aerial vehicles as tools for forest-fire fighting. For. Ecol. Manag. 2006, 234, S263. [CrossRef]

63. Stow, D.A.; Riggan, P.J.; Storey, E.A.; Coulter, L.L. Measuring fire spread rates from repeat pass airborne thermal infrared imagery. Remote Sens. Lett. 2014, 5, 803-812. [CrossRef]

64. Stow, D.A.; Riggan, P.J.; Schag, G.; Brewer, W.; Tissell, R.G.; Coen, J.L.; Storey, E.A. Assessing uncertainty and demonstrating potential for estimating fire rate of spread at landscape scales based on time sequential airborne thermal infrared imaging. Int. J. Remote. Sens. 2019, 40, 4876-4897. [CrossRef]

65. Valero, M.M.; Rios, O.; Planas, E.; Pastor, E. Automated location of active fire perimeters in aerial infrared imaging using unsupervised edge detectors. Int. J. Wildland Fire 2018, 27, 241-256. [CrossRef]

66. Loboda, T.V.; Csiszar, I.A. Reconstruction of Fire Spread within Wildland Fire Events in Northern Eurasia from the MODIS Active Fire Product. Glob. Planetary Chang. 2007, 56, 258-273. [CrossRef]

67. Wooster, M.J. Small-scale experimental testing of fire radiative energy for quantifying mass combusted in natural vegetation fires. Geophys. Res. Lett. 2002, 29, 1-23. [CrossRef]

68. Hudak, A.T.; Freeborn, P.H.; Lewis, S.A.; Hood, S.M.; Smith, H.Y.; Hardy, C.C.; Kremens, R.J.; Butler, B.W.; Teske, C.; Tissell, R.G. The Cooney ridge fire experiment: An early operation to relate pre-, active, and post-fire field and remotely sensed measurements. Fire 2018, 1, 10. [CrossRef]

69. Paugam, R.; Wooster, M.J.; Roberts, G. Use of handheld thermal imager data for airborne mapping of fire radiative power and energy and flame front rate of spread. IEE Trans. Geosci. Remote Sens. 2013, 51, 3385-3399. [CrossRef]

70. Storey, M.A.; Price, O.F.; Sharples, J.J.; Bradstock, R.A. Drivers of long-distance spotting during wildfires in south-eastern Australia. Int. J. Wildland Fire 2020, 29, 459-472. [CrossRef]

71. Riggan, P.J.; Hoffman, J.W. FireMapper ${ }^{\mathrm{TM}}$ : A thermal-imaging radiometer for wildfire research and operations. In Proceedings of the 2000 IEEE Aerospace Conference Proceedings, Big Sky, MT, USA, 25-25 March 2000; Volume 6, pp. $132-135$.

72. Leica Geosystems GIS \& Mapping. ERDAS Imagine; Leica Geosystems: Atlanta, GA, USA, 2006.

73. Gorelick, N.; Hancher, M.; Dixon, M.; Illyushchenko, S.; Thau, D.; Moore, R. Google earth engine: Planetary-scale geospatial analysis for everyone. Remote Sens. Environ. 2017, 202, 18-27. [CrossRef]

74. Benoit, J.W.; Chen, S.C. FireBuster: A Tool for Fire Management; Pacific Southwest Research Station General Technical Report; USDA Forest Service: Ogden, UT, USA, 2019; Volume 261, pp. 25-37.

75. ESRI 2020. ArcGIS Pro Desktop. Release 2.5.0; Environmental Systems Research Institute: Redlands, CA, USA, 2020.

76. Motohka, T.; Nasahara, K.N.; Oguma, H.; Tsuchida, S. Applicability of green-red vegetation index for remote sensing of vegetation phenology. Remote Sens. 2010, 2, 2369-2387. [CrossRef]

77. Storey, E.A.; Stow, D.A.; Roberts, D.A. Evaluating uncertainty in Landsat-derived postfire recovery metrics due to terrain, soil, and shrub type variations in southern California. GIScience Remote Sens. 2020, 57, 352-368. [CrossRef] [PubMed]

78. Barnes, R. RichDEM: Terrain Analysis Software. Python Library. 2016. Available online: https://github.com/r-barnes/richdem (accessed on 21 January 2020).

79. Burrough, P.A.; McDonell, R.A. Principles of Geographical Information Systems; Oxford University Press: New York, NY, USA, 1998; p. 190.

80. Baston, D. Exactextractr: Fast Extraction from Raster Datasets Using Polygons R PACKAGE Version 0.1; R Core Team: Vienna, Austria, 2019.

81. Sandberg, D.V.; Riccardi, C.L.; Schaaf, M.D. Fire potential rating for wildland fuelbeds using the Fuel Characteristic Classification System. Can. J. For. Res. 2007, 37, 2456-2463. [CrossRef]

82. R Core Team. R: A Language and Environment for Statistical Computing; R Foundation for Statistical Computing: Vienna, Austria, 2010. Available online: http:/ / www.R--project.org/ (accessed on 1 January 2019).

83. James, G.; Witten, D.; Hastie, T.; Tibshirani, R. An Introduction to Statistical Learning; Springer: New York, NY, USA, 2013.

84. McKight, P.E.; Najab, J. Kruskal-Wallis Test. In The Corsini Encyclopedia of Psychology; Wiley: Hoboken, NJ, USA, $2010 ;$ pp. 1-4.

85. Stone, M.; Brooks, R.J. Continuum regression: Cross-validated sequentially constructed prediction embracing ordinary least squares, partial least squares and principal components regression. J. R. Stat. Society. 1990, 52, 237-258. [CrossRef]

86. O'Brien, R.M. A caution regarding rules of thumb for variance inflation factors. Qual. Quant. 2007, 41, 673-690. [CrossRef]

87. Pawlowsky-Glahn, V.; Buccianti, A. Compositional Data Analysis: Theory and Applications; Wiley: Hoboken, NJ, USA, 2011.

88. MacNally, R.; Walsh, C.J. Hierarchical partitioning public-domain software. Biodivers. Conserv. 2004, 13, 659-660.

89. Moritz, M.A.; Moody, T.J.; Krawchuk, M.A.; Hughes, M.; Hall, A. Spatial variation in extreme winds predicts large wildfire locations in chaparral ecosystems. Geophys. Res. Lett. 2011, 37, 4. [CrossRef]

90. Viedma, O.; Angeler, D.G.; Moreno, J.M. Landscape structural features control fire size in a Mediterranean forested area of central Spain. Int. J. Wildland Fire 2009, 18, 575-583. [CrossRef]

91. Holsinger, L.; Parks, S.A.; Miller, C. Weather, fuels, and topography impede wildland fire spread in western US landscapes. For. Ecol. Manag. 2016, 380, 59-69. [CrossRef]

92. Vega, J.A.; Fernandes, P.; Cuiñas, P.; Fontúrbel, M.T.L.; Pérez, J.R.; Loureiro, C. Fire spread analysis of early summer field experiments in shrubland fuel types of northwestern Iberia. Forest Ecol. Manag. 2006, 234, S102. 
93. Catchpole, W.R.; Bradstock, R.A.; Choate, J.; Fogarty, L.G.; Gellie, N.; McCarthy, G.J.; McCaw, W.L.; Marsden-Smedley, J.B.; Pearce, G. Co-operative development of equations for heathland fire behavior. In Proceedings of the 3rd International Conference on Forest Fire Research and 14th Conference on Fire and Forest Meteorology, Luso, Portugal, 16-20 November 1998; Volume 2, pp. 16-20.

94. Sharples, J.J.; McRae, R.H.; Wilkes, S.R. Wind-terrain effects on the propagation of wildfires in rugged terrain: Fire channelling. Int. J. Wildland Fire 2012, 21, 282-296. [CrossRef]

95. Clark, T.; Jenkins, M.A.; Coen, J.; Packham, D. A Coupled Atmospheric-Fire Model: Convective Froude number and Dynamic Fingering. Int. J. Wildland Fire 1996, 6, 177-190. [CrossRef]

96. Coen, J.L.; Giglio, L.; Schroeder, W.; Tarnay, L.; Conway, S.; Quayle, B.; Stavros, E.N.; Schimel, D.; Stow, D.A.; Riggan, P.J. Whys and hows of large wildfires: Wind-driven, plume-driven and fire phenomena. In Proceedings of the 8th International Conference on Fire Ecology, Tucson, AZ, USA, 18-22 November 2019.

97. De Reu, J.; Bourgeois, J.; Bats, M.; Zwertvaegher, A.; Gelorini, V.; De Smedt, P.; Chu, W.; Antrop, M.; De Maeyer, P.; Finke, P.; et al. Application of the topographic position index to heterogeneous landscapes. Geomorphology 2013, 186, 39-49. [CrossRef] 